University of Arkansas, Fayetteville

ScholarWorks@UARK

Graduate Theses and Dissertations

$12-2017$

\title{
DEM Study of a Single Stone Column in a Clayey Stratum
}

Anibal Enrique Santos

University of Arkansas, Fayetteville

Follow this and additional works at: https://scholarworks.uark.edu/etd

Part of the Civil Engineering Commons, and the Geotechnical Engineering Commons

\section{Citation}

Santos, A. E. (2017). DEM Study of a Single Stone Column in a Clayey Stratum. Graduate Theses and Dissertations Retrieved from https://scholarworks.uark.edu/etd/2617

This Thesis is brought to you for free and open access by ScholarWorks@UARK. It has been accepted for inclusion in Graduate Theses and Dissertations by an authorized administrator of ScholarWorks@UARK. For more information, please contact scholar@uark.edu. 
DEM Study of a Single Stone Column in a Clayey Stratum

A thesis submitted in partial fulfilment of the requirements for the degree of Master of Science in Civil Engineering

by

Aníbal Enrique Santos Marín

Technological University of Panama

Bachelor of Science in Civil Engineering, 2010

December 2017

University of Arkansas

This thesis is approved for recommendation to the Graduate Council

Michelle L. Bernhardt, Ph.D.

Thesis Director

Richard A. Coffman, Ph.D.

Clinton M. Wood, Ph.D.

Committee Member

Committee Member 


\section{ABSTRACT}

Aggregate piers are an alternative ground improvement technique used for improving the bearing capacity and reducing the total and differential settlement of foundations supported on compressible soils. The piers are composed of a series of vibrationally compacted aggregate lifts from a desired depth up to the finished foundation level. The shear strength of the coarse-grained material comprising an aggregate pier is defined by its internal friction angle. There are several factors affecting the friction angle of the granular material that include: confining stress, particle shape, relative density and particle distribution (gradation). These factors are not directly considered in the design of aggregate columns. However, because the granular material friction angle is a fundamental design parameter used to estimate the bearing capacity of aggregate piers, these factors could play an important role in the mechanical behavior of isolated aggregate columns. Other factors responsible for altering the global performance of aggregate piers are column length and the undrained shear strength of the matrix soil. Full-scale 3D discrete element method (DEM) simulations were conducted to reproduce field plate load tests performed on small circular foundation resting on single aggregate piers in order to evaluate the effects of these factors on the global performance of aggregate columns. The numerical results demonstrate that incorporating the gradation, confining stress and relative density dependence of the aggregate friction angle in the DEM models provides better numerical estimation of the loaddisplacement curves observed in the field for both the foundation serviceability level and the ultimate load condition. The effects of column length on the load-displacement response are found to be a minimum for column slenderness ratios greater than four. 


\section{ACKNOWLEDGMENTS}

I want to thank my wife, Carolina, family and friends who have supported me during all this academic journey. Also, I would like to thank my advisor, Dr. Michelle Bernhardt, for her encouragement in developing this thesis. Finally, I would like to thank Dr. Richard Coffman and Dr. Clinton Wood for being part of my committee. 


\section{DEDICATION}

I would like to dedicate this work to my Lord, Jesus Christ, my wonderful wife, Carolina, and my mother, Enriqueta. 


\section{TABLE OF CONTENTS}

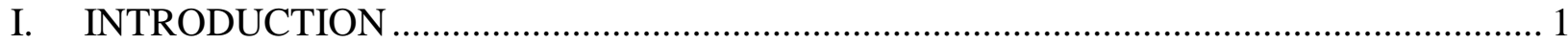

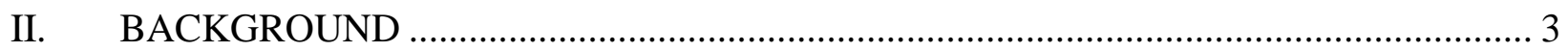

III. METHODOLOGY AND NUMERICAL SIMULATION _............................................ 9

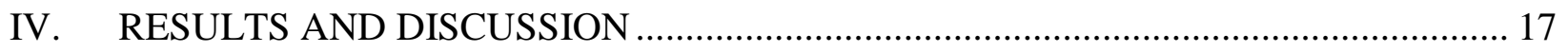

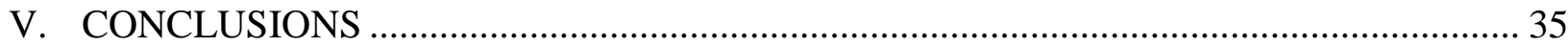

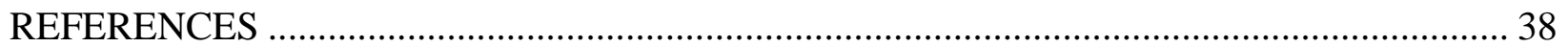




\section{LIST OF TABLES}

Table 1. Foundation and Stone Column Geometry........................................................... 13

Table 2. Elastic and Plastic Material Properties...................................................................... 15

\section{LIST OF FIGURES}

Figure 1. Comparison of well-graded and uniformly-graded gradations (after Duncan et al., 2007; Stuedlein 2008; and Stuedlein et al. 2012). ..................................................................... 4

Figure 2. Variation of the secant friction angle with respect to confining pressure for different relative density (after Duncan et al., 2007 and Newton, 2014) .................................................... 5

Figure 3. Load-displacement curves for the well-graded and uniformly-graded aggregate piers

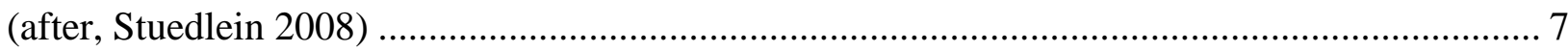

Figure 4. Configuration and geometry of the soil profile under the small footings where plate load tests were conducted. (Based on field information from Stuedlein, 2008) ............................ 11

Figure 5. DEM-mode block generation "mesh", ……............................................................ 12

Figure 6. (a) Su profiles at the locations of small foundations and the stone columns, (b) Approximated su profile used in the model for stone column VP10W (Based on field information from Stuedlein, 2008). 14

Figure 7. Comparison of the load-displacement curve corresponding to the unreinforced soil. . 14 Figure 8. Comparison of the load-displacement curve corresponding to the stone column V10PW for constant friction angles $40^{\circ}, 45^{\circ}$ and $50^{\circ}$, and Eq. (2). 18

Figure 9. Comparison of the load-displacement curve corresponding to the stone column V10PU for constant friction angles $40^{\circ}, 45^{\circ}$ and $50^{\circ}$, and Eq. (3). 
Figure 10. DEM Results for V10PW. (a) Comparison of the DEM load-displacement curve with field results, (b) Radial displacement, (c) Average confining stress distribution with depth, (d) Settlement distribution with depth for $\mathrm{Q}=885 \mathrm{kPa}$. 22

Figure 11. DEM Results for V15PW. (a) Comparison of the DEM load-displacement curve with field data, (b) Radial displacement, (c) Average confining stress distribution with depth, (d) Settlement distribution with depth for $\mathrm{Q}=895 \mathrm{kPa}$. 23

Figure 12. DEM Results for V10PU. (a) Comparison of the DEM load-displacement curve with field data, (b) Radial displacement, (c) Average confining stress distribution with depth, (d)

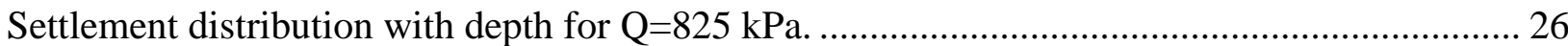

Figure 13. DEM Results for V15PU. (a) Comparison of the DEM load-displacement curve with field data, (b) Radial displacement, (c) Average confining stress distribution with depth, (d) Settlement distribution with depth for $\mathrm{Q}=840 \mathrm{kPa}$. 27

Figure 14. DEM Results for V10U. (a) Comparison of the DEM load-displacement curve with field data, (b) Radial displacement, (c) Average confining stress distribution with depth, (d) Settlement distribution with depth for $\mathrm{Q}=810 \mathrm{kPa}$. 30

Figure 15. DEM Results for V15U. (a) Comparison of the DEM load-displacement curve with field data, (b) Radial displacement, (c) Average confining stress distribution with depth, (d) Settlement distribution with depth for $\mathrm{Q}=840 \mathrm{kPa}$. 31

Figure 16. Comparison of the full DEM load-displacement for columns (V10PW and V10PU) with extrapolated field data. 33

Figure 17. (a) Comparison of the 3DEM load-displacement curves for No.57 and 21b

gradations. (b) Average confining stress with depth. 34 
Figure 18. (a) Comparison of the effect of column length for V15PU. (b) Comparison of the

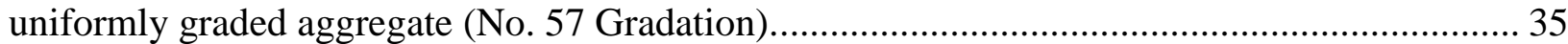




\section{INTRODUCTION}

The need to construct civil engineering projects on weak soils has led geotechnical engineers to develop cost-effective techniques for improving the stiffness and permeability compressible soils. Because they are the most economically viable and environmentally acceptable, vibrated aggregate piers are considered one of the best soil improvement alternatives (Vahedian et al. 2014). Typically, aggregate piers are used for increasing the bearing capacity and decreasing the total and differential settlement of foundations supported on soft to medium stiff fine-grained soils. Other advantages of using aggregate piers include: acceleration of consolidation and permeability, reduction of liquefaction potential (not for fine grain soils) and stabilization of slopes (e.g., Vahedian et al. 2014; Zhang et al. 2013; Ambily et. al 2007; and Stuedlein and Holtz 2012).

Typically for aggregate pier projects, between 15 to $35 \%$ of the treated soil area is substituted with compacted granular material using different types of installation techniques such as vibro-displacement, vibro-replacement or tamping (Nazari and Ghazavi 2012; and Stuedlein and Holtz 2012). When the vibrational installation technique is used, the aggregate piers are better known as stone columns. The effects of the installation methods on the performance of stone columns (i.e. load-displacement response) are insignificant for engineering purposes. The stiffness and strength of the surrounding soil have been showed to have a greater influence in the global behavior of aggregate piers (Stuedlein and Holtz 2012). Stuedlein and Holtz also showed that at small displacements, the column length has a greater influence on the load-displacement curve than the gradation curve or installation method, whereas the inverse behavior was noticed at larger displacements. For the typical coarse-grained material used to construct aggregate piers, Duncan et al. (2007) showed that the gradation, relative density and confining stress $\left(\sigma_{\mathrm{r}}^{\prime}\right)$ have a 
significant impact on the aggregate friction angle $\left(\phi_{\text {sc }}\right)$, which is a crucial parameter for stone column design. Hughes et al. (1974) showed that the ultimate confining pressure ( $\left.\sigma_{\mathrm{r} \text {, ult }}^{\prime}\right)$ increases as the undrained shear strength of the surrounding soil $\left(\mathrm{s}_{\mathrm{u}}\right)$ increases, which means that $\phi_{\text {sc }}$ is also a function of $\sigma_{\mathrm{r} \text {, ult }}$ and $\mathrm{s}_{\mathrm{u}}$ due to the curvature of Mohr's failure envelope (Stuedlein and Holtz, 2013).

Methods for predicting the bearing capacity of an isolated stone column consist of analytical or semi-empirical methods (e.g., Greenwood 1970; Vesic 1972; Hughes et al. 1974, 1975; Stuedlein and Holtz 2013; and Bouassida and Frikha 2015), and empirical methods which are based on calibrations using field load tests (e.g., Mitchell et. al 1981; and Barksdale and Bachus 1983). These existing methods do not directly consider the effects of the parameters such as aggregate gradation, relative density and friction angle-confining pressure dependence. Therefore, the purpose of this study is to numerically determine the influence of these parameters on the load-displacement response and bulging zone formation. The effect of the column length on the load-displacement response is also investigated.

The content of this thesis covers: A literature review that includes a description of the global mechanical behavior of stone columns including the main factors influencing the loaddisplacement response of stone columns (Section II). A description of the methodology used to numerically replicate plate load tests using 3D-DEM simulations as well as how the material properties were estimated and calibrated (Section III). Discussion and comparison of the DEM numerical results with the field database used as a reference (Section IV). A summary of the main findings of this numerical investigation and a recommendation of possible lines of research (Section V). 


\section{BACKGROUND}

Based on the analytical, semi-empirical and empirical methods for estimating the bearing capacity, the main material properties that affect the overall performance of isolated stone columns include: $s_{\mathrm{u}}, \phi_{\mathrm{sc}}^{\prime}$, and the Young's modulus of the surrounding soil $\left(\mathrm{E}_{\mathrm{s}}\right)$; with $\phi_{\text {sc }}^{\prime}$ and $\mathrm{su}_{\mathrm{u}}$ being the most important. The stone column diameter $\left(D_{s c}\right)$ and length $\left(L_{s c}\right)$ also play a notable role in the mechanical behavior of single stone columns. According to Hughes and Withers (1974), bulging is the failure mechanism that controls the performance of isolated stone columns with $\mathrm{L}_{\mathrm{sc}} / \mathrm{D}_{\mathrm{sc}}$ ratios greater than 4. Barksdale and Bachus (1983) mentioned that regardless of the tip column condition (end bearing or free floating) stone columns with slenderness ratios greater than 3 fail in bulging. The bulging formation is fundamentally controlled by the confining resistance that the adjacent matrix soil can provide to the column. At the failure condition, this ultimate confining resistance strongly depends on the strength and stiffness (specifically the $\mathrm{s}_{\mathrm{u}}$ and $\mathrm{E}_{\mathrm{s}}$ ) of the matrix soil (Hughes et al. 1974, 1975). Consequently, the selection of a representative $s_{u}$ value corresponding to the bulging formation is key for the bearing capacity estimation. Many authors (Hughes 1974; Barskdale et al. 1983; Ambily and Gandhi 2007; and Nazari et al. 2012) have suggested that the bulging formation occurs at depths ranging from 2 to 3D sc. Brauns (1978) developed the Eq. (1) to estimate the bulging zone length (h), which is a function of $D_{\mathrm{sc}}$ and $\phi_{\mathrm{scc}}^{\prime}$. Based on this equation, and the fact that $\phi_{\mathrm{sc}}^{\prime}$ depends on the $\sigma_{\mathrm{r}}^{\prime}$, the gradation of the granular material is likely to have some influence on the bulging zone formation. Based on the bulging failure mechanism, the major part of the bearing pressure applied on the surface of a stone column is radially distributed to the adjacent matrix soil at the bulging zone length, and only a small percentage is transferred to the firm or floating column support. Therefore, a significant increase in $\sigma_{r}^{\prime}$ could occur during this loading procedure. 


$$
\mathrm{h}=\mathrm{D}_{\mathrm{sc}}\left(\tan \left(45^{\circ}+\frac{\phi^{\prime}{ }_{\mathrm{sc}}}{2}\right)\right)
$$

The coarse granular material used for building stone columns is generally gravel, crushed rock (typically limestone), or waste rock. The selection of the aggregate gradation depends on the installation method, column length and diameter, and groundwater table, but it generally varies in particle sizes from $6 \mathrm{~mm}$ to $50 \mathrm{~mm}$ (Barksdale and Bachus, 1983). The aggregate gradation curve and relative density are parameters that are typically not taken into account for stone column design. Figure 1 illustrates two typical gradations used to construct aggregate piers which were experimentally investigated by Duncan et al. 2007, Stuedlein 2008, and Newton 2014. Duncan et al. (2007) investigated the effects that gradation, relative density and confining stress have on $\phi_{\text {sc. }}^{\prime}$ Based on the results obtained from triaxial tests, the authors observed that $\phi_{\text {sc }}$ linearly decreases as a logarithmic function of the $\sigma_{r}^{\prime}$ for both gradations (uniformly-graded aggregate, No. 57 gradation) and well-graded aggregate, 21b gradation) as shown in Figure 2.

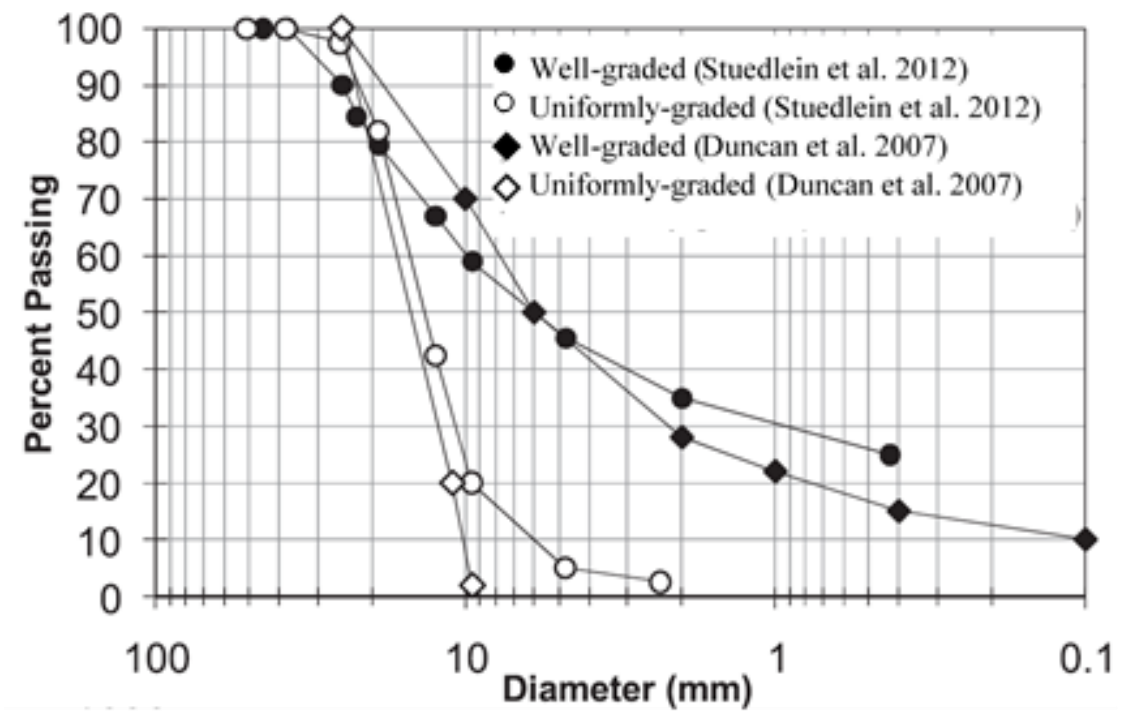

Figure 1. Comparison of well-graded and uniformly-graded gradations (after Duncan et al., 2007, Stuedlein 2008, and Stuedlein et al. 2012). 


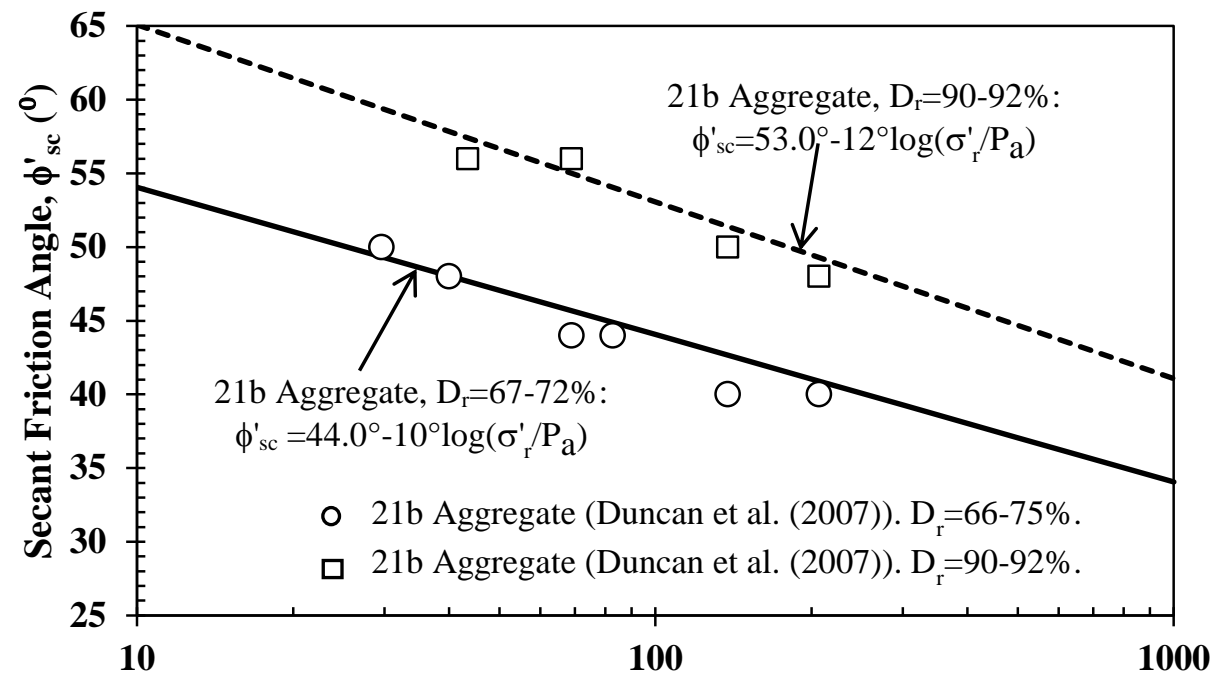

Confining Pressure, $\sigma_{\mathbf{r}}{ }_{\mathbf{r}}(\mathbf{k P a})$

(a) Well-graded $21 \mathrm{~b}$ aggregate.

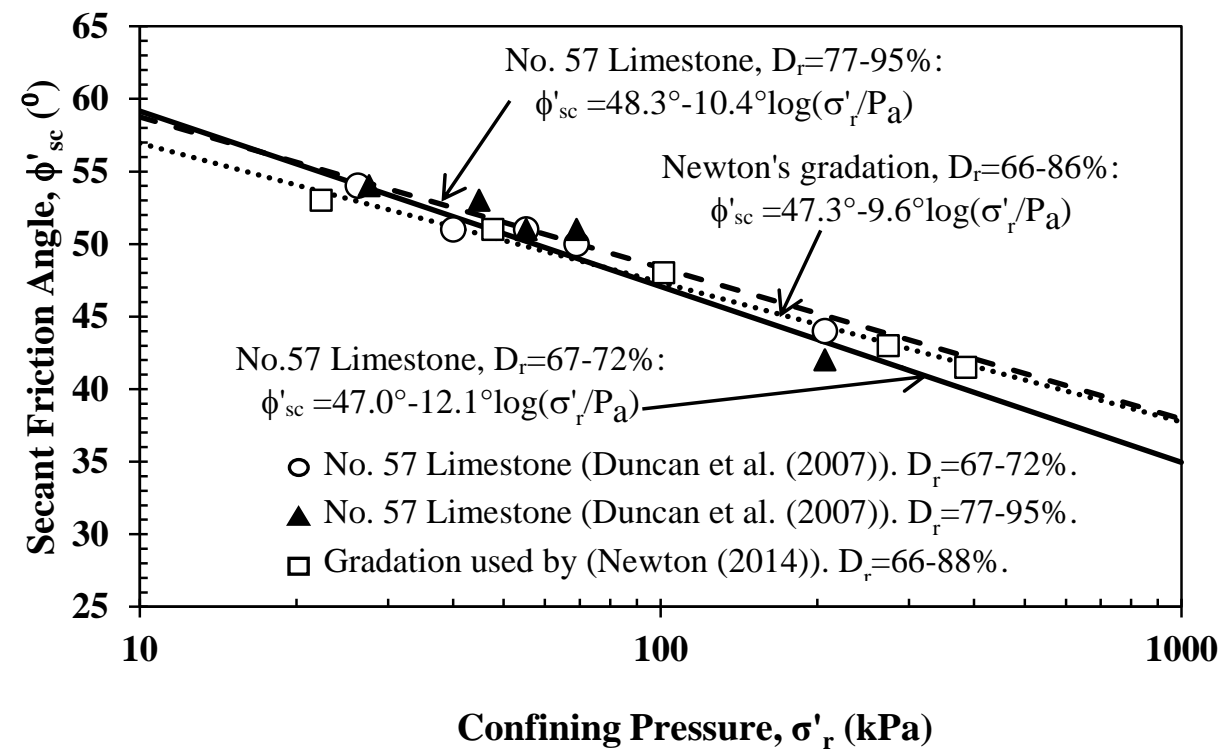

(b) Uniformly-graded No.57 aggregate

Figure 2. Variation of the secant friction angle with respect to confining pressure for different relative density (after Duncan et al., 2007 and Newton, 2014)

For the $21 \mathrm{~b}$ gradation, the specimens with low relative density $(67-72 \%)$ have a $\phi_{\mathrm{sc}}^{\prime}$ that is around $10^{\circ}$ lower than that obtained for the densest samples as illustrated in Figure 2 (a). On the other hand, for the uniformly-graded aggregate, $\phi_{\mathrm{sc}}^{\prime}$ is not significantly affected by the relative density as shown in Figure 2 (b). Newton (2014) conducted laboratory experiments to 
investigate the variation of $\phi_{\mathrm{sc}}$ with $\sigma_{\mathrm{r}}^{\prime}$ for the uniformly-graded aggregate used by Stuedlein (2008) to construct a series of aggregate piers. The $\phi_{\text {sc }}^{\prime}$ equation developed by Newton (2014) is very similar to that obtained by Duncan et al. (2007) for a similar relative density range.

McCabe et al. (2009) mentioned that if the bottom feed installation method is used, it is conservative to employ a design $\phi_{\text {sc }}^{\prime}$ of $40^{\circ}$ to estimate the settlement of a stone column under a widespread loading scenario; however, it might be unconservative if the column is installed using the top feed method. Herle et al. (2008) suggested that the performance of aggregate piers not only depends on the confining pressure, but also on the particle gradation curve, as well as particle shapes and sizes. Additionally, Herle et al. mentioned that at low levels of confining stress, the $\phi_{\text {sc }}^{\prime}$ is greater than $50^{\circ}$ for the typical types of granular materials used to construct vibrated aggregate piers, so that it would be conservative to use a $\phi^{\prime}$ sc of $40^{\circ}$. Stuedlein and Holtz (2013) utilized a $\phi_{\text {sc }}$ of $45^{\circ}$ to estimate the bearing capacity of the single stone columns referenced in this study. Usually, a constant internal $\phi^{\prime}$ sc (between $40^{\circ}$ to $50^{\circ}$ ) is used to estimate the bearing capacity of a single stone column. If $\phi^{\prime}$ sc values of $40^{\circ}, 45^{\circ}$ and $50^{\circ}$ are used in the equation developed by Hughes et al. (1975), the estimated bearing capacities using $\phi$ 'sc equal to $45^{\circ}$ and $50^{\circ}$ would be $26 \%$ and $63 \%$ greater than that obtained using a $\phi_{\text {sc }}^{\prime}$ of $40^{\circ}$, respectively. This shows that even when a constant $\phi_{\text {sc }}^{\prime}$ is used for design, the effect of selecting an appropriate $\phi$ 'sc is important to estimate the bearing capacity. Additionally, if the mobilized friction angle decreases $10^{\circ}$ as a result of an increase in the $\sigma_{r}^{\prime}$ of $180 \mathrm{kP}_{\mathrm{a}}$ as shown in Figure 2, the reduction of the bearing capacity could be significant, and it needs to be considered for design. 
Stuedlein (2008) conducted a full-scale field testing program to determine the effect that parameters such as aggregate gradation, column length, and installation methods have on the performance of aggregate piers. The gradation designation is represented by the "W" for wellgraded, and the "U" is used for uniformly-graded aggregate. The lengths of the columns (3.05 m and $4.57 \mathrm{~m}$ ) are symbolically expressed in feet for each pier, whereas the installation methods are designated by the "P" for predrilling, and the "V" is utilized for vibrational procedure. Figure 3 illustrates the load-displacement curves for six of the twenty full-scale field plate load tests conducted by Stuedlein (2008). For columns V10PW and V15PW, the load-displacement responses are identical; however, for the uniformly-graded aggregate, more variability is observed in the load-displacement responses, which appear to be influenced by the column length, compaction method, and column locations.

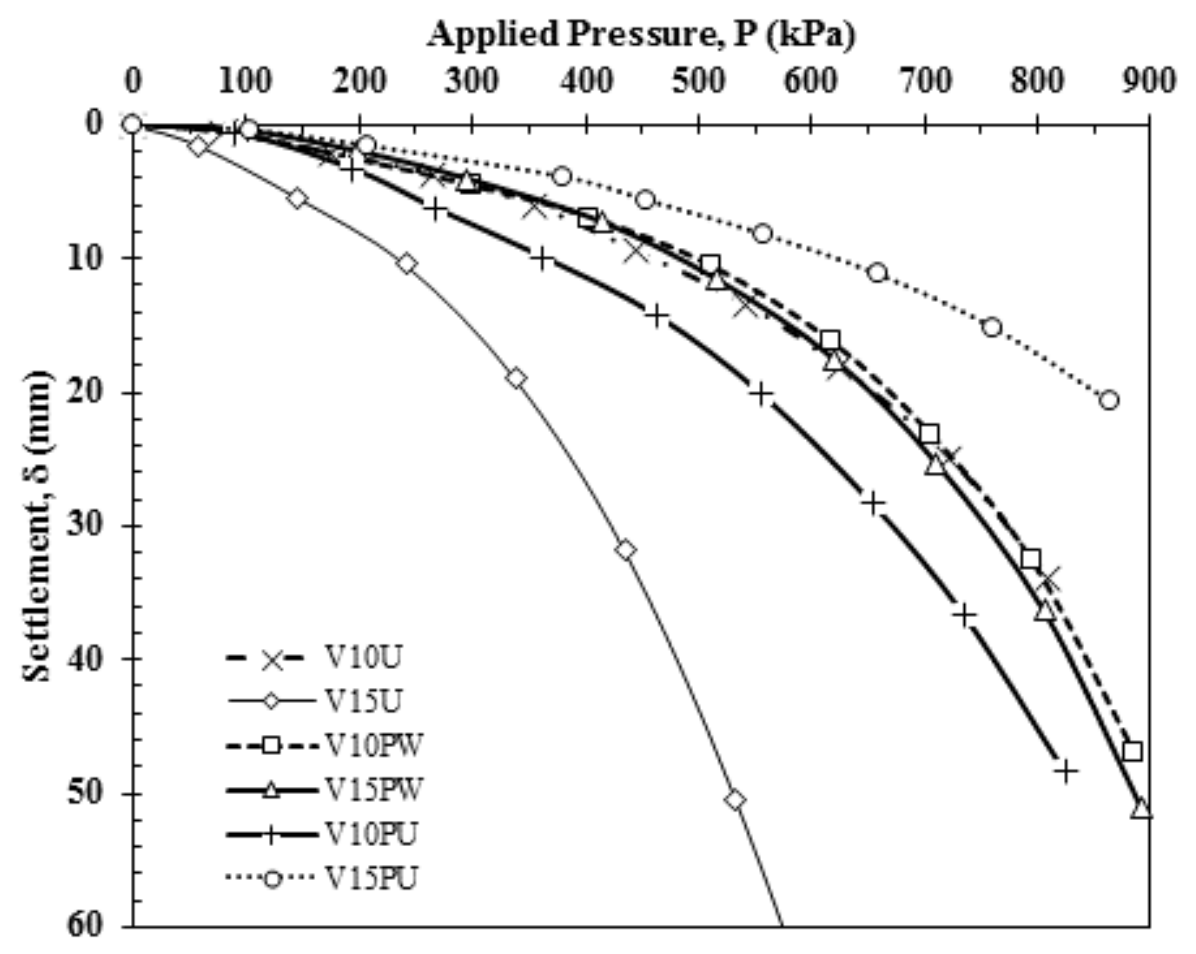

Figure 3. Load-displacement curves for the well-graded and uniformly-graded aggregate piers (after, Stuedlein 2008) 
Even though differences were observed in the performance of the aggregate piers (loaddisplacement curves) due to the use of different aggregate gradations as shown in Figure 3, Stuedlein et al., (2012) reported that aggregate gradation effects do not appear to be statistically significant. However, Stuedlein et al. (2013) mentioned that the deviations of the bearing capacity $\left(\mathrm{N}_{\mathrm{p}}\right.$ ) and cavity expansion factors $\left(\mathrm{k}_{\mathrm{p}}\right)$ for estimating the bearing capacity of isolated aggregate piers could be caused by the aggregate gradation variances.

Stuedlein et al. (2012) reported that for the aggregate piers built with uniformly-graded aggregate, the column length seems to increase the initial stiffness of the piers. The $4.6 \mathrm{~m}$ long columns provided greater bearing resistance than those $3 \mathrm{~m}$ long. On the other hand, for wellgraded piers, the column length does not seem to affect the load-displacement curve (Stuedlein et al., 2012). These observations were made considering more field data than what is shown in Figure 3. According to Vahedian et al. (2014), stone columns with lengths greater than the critical length, which could be estimated as 4 to 6 times $\mathrm{D}_{\mathrm{sc}}$, do not improve the loaddisplacement response. However, longer columns might be needed to meet settlement design requirements. The slenderness ratios of aggregate piers investigated by Stuedlein (2008) are 4 and 6. Therefore, the increase or decrease in the stiffness of piers with uniform-graded aggregate might not be due to the length of the pier; however, this needs to be investigated.

Stuedlein et al. $(2012,2013)$ reported that there is notable variation in the performance of the existing analytical approaches for estimating the bearing capacity of aggregate piers with respect to the responses obtained from the full-scale experimental program conducted by Stuedlein (2008). This results in a lack of confidence in these methods. In the case of the semiempirical and empirical approaches, their use is restricted to field project conditions that are within the range of the field data (geometry and material properties) used to calibrate those 
methods. Therefore, the full-scaled experimental database obtained by Stuedlein (2008) provides an excellent opportunity to calibrate 3D-DEM numerical models that can help investigate the parameters affecting the global performance of isolated aggregate columns.

Because of the granular composition of stone columns, their internal particle-particle interactions cannot be properly captured using continuous analytical and numerical methods (Ngo et al., 2016). Hence, to better represent this particle interaction, it is advantageous to use a numerical approach capable of modeling the stone column aggregate as a discontinued material. This can be achieved by using the discrete element method (DEM), which is a numerical methodology employed to compute the mechanical behavior (stress and deformation) of a volume composed of a large number of granular particles (Cundall,1988; and Luding, 2008).

The global performance of a vibrated aggregate column is generally corroborated in the field by conducting a plate load test on it, and determining the load-displacement curve that corresponds to that column. Hence, this study is focused on using 3D-DEM simulations to numerically replicate six of the twenty full-scale field plate load tests performed by Stuedlein (2008). The plate load tests were conducted on circular small foundations resting on single stone columns which are $3 \mathrm{~m}$ and $4.6 \mathrm{~m}$ long. The piers were installed in a clayey stratum known as the Beaumont clay formation located in Baytown, Texas.

\section{METHODOLOGY AND NUMERICAL SIMULATIONS}

Because of the discrete behavior of the coarse-grained material comprising a stone column, simulating the aggregate utilizing DEM offers a better understanding of the micromechanical particle-particle interaction. The computational platform 3DEC by Itasca Consulting Group, Inc. was used in this study. 3DEC employs discrete "blocks" which interact 
through boundary conditions (joints) to simulate discontinuous media. Each individual block can be discretized into fine tetrahedral zones. Depending on the block and joint constitutive models and the zone generation type, each block can behave as either a rigid or deformable element. The block zone generation plays an important role in the performance and efficiency of a DEM model in 3DEC. There are three different tetrahedral zone types available in 3DEC: regular tetrahedral, high-order tetrahedral and quadrilateral zoning better known as mixed discretization. Mixed discretization zoning was used to refine the blocks in this study because it is recommended for models that involve high plastic deformation (Itasca Consulting Group Inc., 2013)

The six 3D DEM simulations performed in this numerical investigation are replications of plate load tests conducted by Stuedlein (2008) on 0.76-m-diameter concrete footings completely embedded into a stratified clayey soil, and supported on aggregate piers. The field load displacement curves corresponding to these piers (V10PW, V10PU, V15PW, V15PU, V10U and V15U) as shown in Figure 3 were used as the references to validate the results obtained from the 3D DEM simulations. Figure 4 shows the general soil stratigraphy corresponding to where the load tests were performed, along with the model geometry and boundary conditions. The soil profile is composed of four layers which are very stiff desiccated clay, medium stiff low plasticity clay (CL), sandy silt/silty sand (SM/ML) and stiff high plasticity clay $(\mathrm{CH})$. The $(\mathrm{SM} / \mathrm{ML})$ layer was treated as cohesive soil based on the su profile because the thickness of the layer was considered to be negligible. 


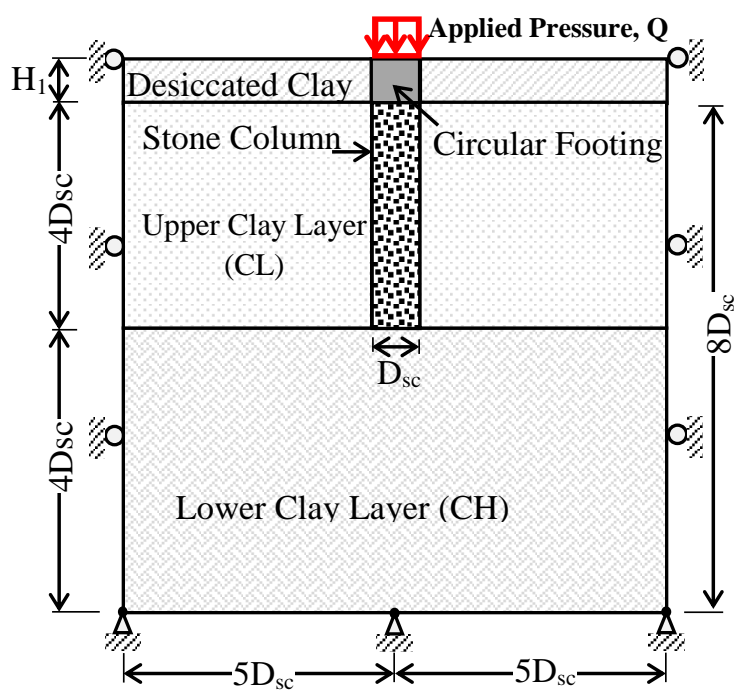

a) Stone Columns with $\mathrm{L}_{\mathrm{sc}}=4 \mathrm{D}_{\mathrm{sc}}$

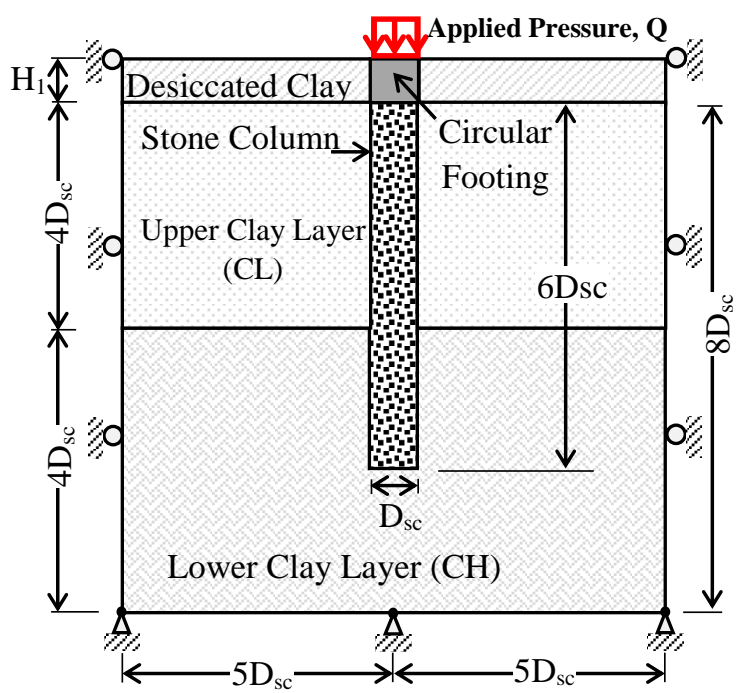

b) Stone Columns with $\mathrm{L}_{\mathrm{sc}}=6 \mathrm{D}_{\mathrm{sc}}$

Figure 4. Configuration and geometry of the soil profile under the small footings where plate load tests were conducted. (Based on field information from Stuedlein, 2008)

Figure 5 illustrates the model block generation in 3DEC. Additional block refinement was developed around the stone column in order to improve the resolution of the confining stress distribution and the bulging zone formation. The desiccated clay crust was simulated as a material rather than a surcharge load to consider its stiffness. The polyhedral faces are not shown in the views for clarity. The geometries of the small footing and stone columns are summarized in Table 1. The footing embedment depth $\left(\mathrm{H}_{1}\right)$ is $0.61 \mathrm{~m}$, and it was assumed to be the same for all of the columns. Columns V10PW and V15PW were constructed using the well-graded gradation, whereas the columns, V10PU, V15PU, V10U and V15U, utilized the uniformlygraded aggregate described in Figure 1. All of the columns were installed using the bottom feed method. Since the six stone columns were constructed with gradations similar to those investigated by Duncan et al. (2007), the relationship developed by Duncan et al. to describe how $\phi_{\text {sc }}^{\prime}$ varies with $\sigma_{\mathrm{r}}^{\prime}$ was considered applicable for simulating all of the piers. 


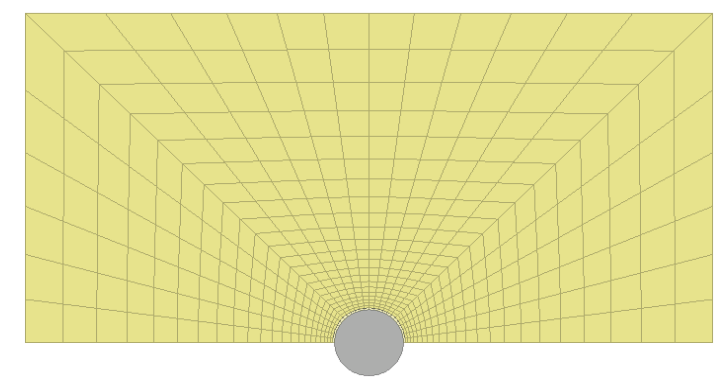

a) DEM model- plan view

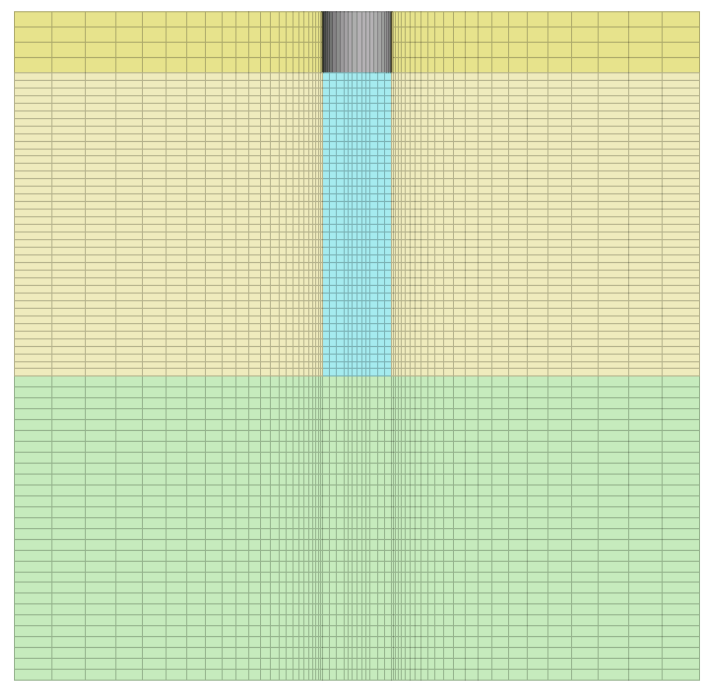

b) DEM model- profile

Figure 5. DEM-mode block generation "mesh".

Because the uniformly-graded aggregate investigated by Newton (2014) is identical to the one that was used by Stuedlein (2008) to construct all of the " $U$ " designated columns, a simulation was performed to validate that the Duncan et al. (2007) equation is appropriate for the well-graded aggregate, as well as for the uniformly-graded aggregate. Figure 6 (a) illustrates the corresponding $\mathrm{s}_{\mathrm{u}}$ profile at the locations of the six stone columns and two small footings modeled in this study. These Kriged $s_{u}$ profiles were obtained from the field and statistical investigation conducted by Stuedlein (2008) in the Beaumont clay formation. The $\mathrm{s}_{\mathrm{u}}$ profile was subdivided into small sublayers $\left(0.30 \mathrm{~m}\right.$ thick) to create a more representative $\mathrm{s}_{\mathrm{u}}$ value at the bulging zone. 
This further refinement also allowed for better resolution of the confining stresses within the bulging zone.

Table 1. Foundation and Stone Column Geometry

\begin{tabular}{c|cccc}
\hline Element & $\begin{array}{c}\text { Diameter, D or } \mathrm{D}_{\mathrm{sc}} \\
{[\mathrm{m}]}\end{array}$ & $\begin{array}{c}\text { Length, } \mathrm{L}_{\mathrm{sc}} \\
{[\mathrm{m}]}\end{array}$ & $\begin{array}{c}\mathrm{L}_{\mathrm{sc}} / \mathrm{D}_{\mathrm{sc}} \text { ratio } \\
---\end{array}$ & $\begin{array}{c}\text { Replacement Area Ratio, } \mathrm{A}_{\mathrm{r}} \\
{[\%]}\end{array}$ \\
\hline V10PW & 0.76 & 3.05 & 4 & 100 \\
\hline V15PW & 0.76 & 4.57 & 6 & 100 \\
\hline V10PU & 0.74 & 3.05 & 4 & 97 \\
\hline V15PU & 0.74 & 4.57 & 6 & 97 \\
\hline V10U & 0.71 & 3.05 & 4 & 93 \\
\hline V15U & 0.74 & 4.57 & 6 & 97 \\
\hline Foundation & 0.76 & 0.61 & --- & -- \\
\hline
\end{tabular}

Figure 6 (b) shows the comparison of the field $s_{u}$ profile and the $s_{u}$ profile used to simulate column V10PW. This procedure was employed for all six columns. Undrained conditions were used for modeling the surrounding soil since the load application rate during a plate load test is quick (Stuedlein and Holtz, 2010). Due to their granular composition, the stone columns were modeled using drained conditions. All of the DEM simulations were conducted employing the Mohr Coulomb failure criterion. The undrained Young's modulus for the clayey layers was estimated using Duncan and Buchignani (1976) based on the plasticity index (PI) and overconsolidated ratio (OCR) values obtained from Stuedlein (2008). To verify and calibrate the soil properties used for the matrix soil in the DEM-models, a plate load test was simulated for the unreinforced soil. Figure 7 compares the load-displacement curve obtained from the DEM simulation with the corresponding field data for the footings (P30-1 and P30-2). Good agreement is observed between the DEM simulations and the field results. Therefore, the model parameters used to capture the undrained soil behavior was determined to be validated. Based on the fact that most of the initial applied pressure is carried by the column, the Young's modulus for the 
stone columns was estimated by using the elastic equation developed by Poulos and Davis (1974). The elastic and plastic material properties used in the models are summarized in Table 2.

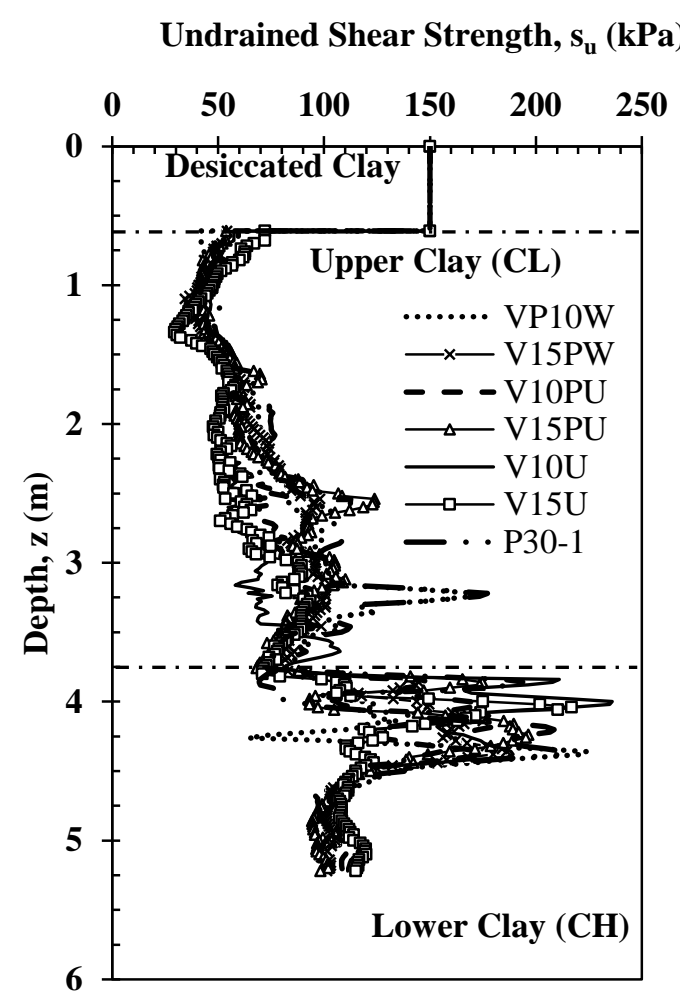

(a) Field $\mathrm{s}_{\mathrm{u}}$ Profiles

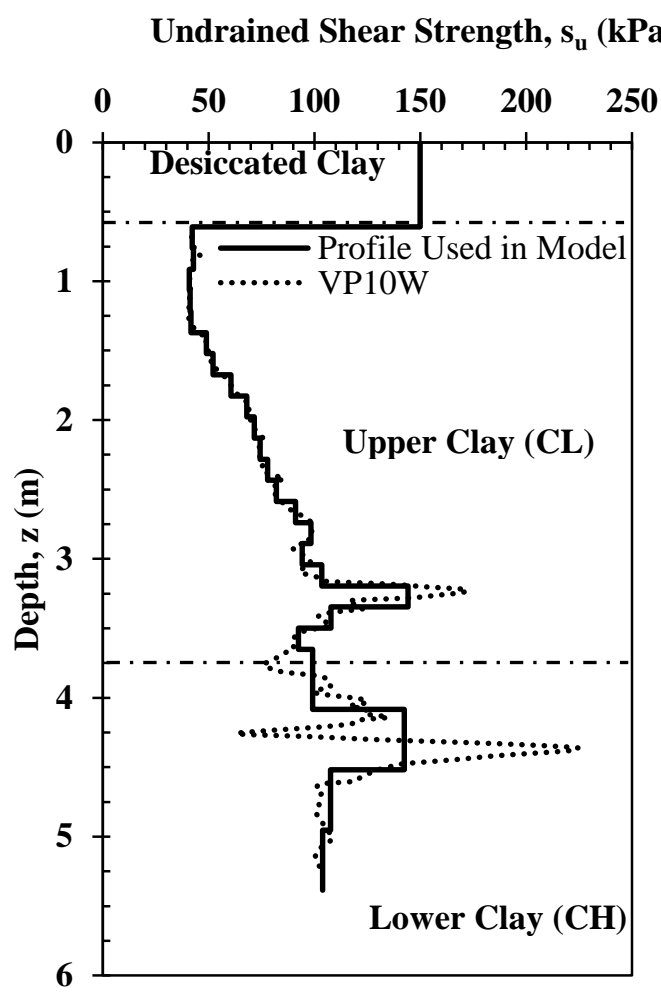

(b) Model $\mathrm{s}_{\mathrm{u}}$ Profile for VP10W

Figure 6. (a) Su profiles at the locations of small foundations and the stone columns, (b) Approximated $s_{u}$ profile used in the model for stone column VP10W (Based on field information from Stuedlein, 2008).

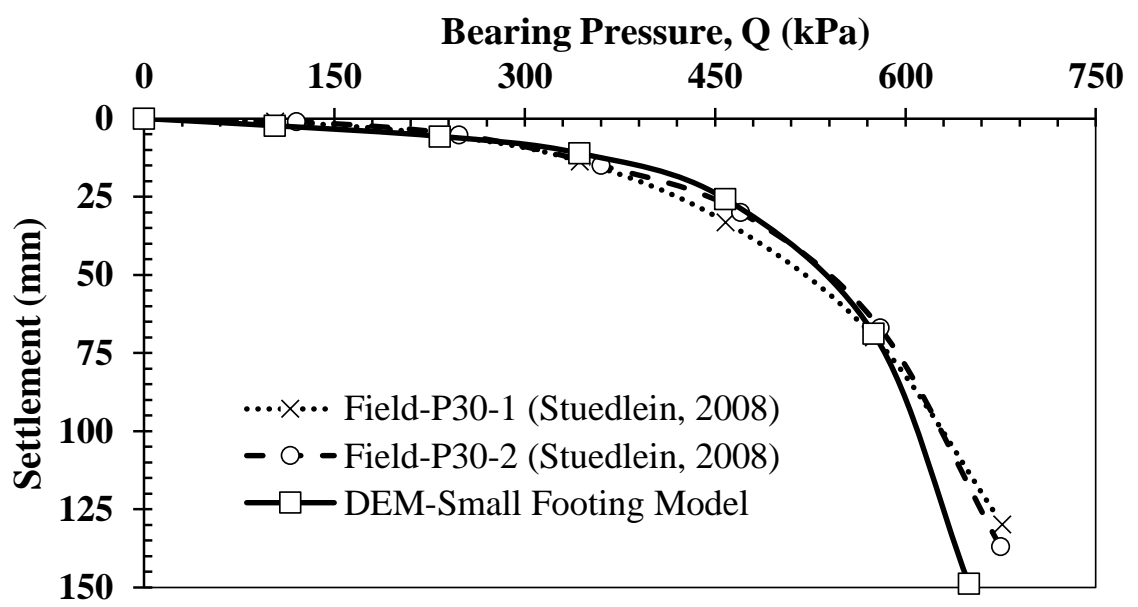

Figure 7. Comparison of the load-displacement curve corresponding to the unreinforced soil. 
To examine the variation of the $\phi_{\mathrm{sc}}^{\prime}$ with $\sigma_{\mathrm{r}}^{\prime}$, an average confining stress was computed for each sublayer. Subsequently, the average confining stress was used in the equations proposed by Duncan et al. (2007) and Newton (2014) (see Table 2, Eq. (2), Eq. (3) and Eq. (4)) to reduce $\phi$ 'sc. This process was repeated for each vertical load increment applied on the surface of the small foundation to replicate a plate load test. In addition to modeling the actual column configurations constructed in the field, simulations were also carried out to examine the influence of aggregate gradation and column length.

Table 2. Elastic and Plastic Material Properties

\begin{tabular}{|c|c|c|c|c|c|c|c|}
\hline Material & $\begin{array}{c}\gamma \\
{\left[\mathrm{kN} / \mathrm{m}^{3}\right]}\end{array}$ & $\begin{array}{c}v \\
--- \\
\end{array}$ & $\begin{array}{c}\mathrm{E} \\
{[\mathrm{MPa}]}\end{array}$ & $\begin{array}{c}\mathrm{S}_{\mathrm{u}} \\
{[\mathrm{kPa}]}\end{array}$ & $\begin{array}{c}\text { PI } \\
{[\%]}\end{array}$ & $\begin{array}{c}\text { OCR } \\
---\end{array}$ & $\underset{\circ}{\phi_{s c}^{\prime}}$ \\
\hline Desiccated Clay & 17 & 0.49 & 30 & 150 & --- & $>20$ & 0 \\
\hline Upper Clay (CL) & 18 & 0.49 & $300 \mathrm{su}_{\mathrm{u}}$ & Figure 4 & 26 & 12 & 0 \\
\hline Lower Clay $(\mathrm{CH})$ & 19 & 0.49 & $230 \mathrm{su}_{\mathrm{u}}$ & Figure 4 & 42 & 6 & 0 \\
\hline $\begin{array}{l}\text { V10PW } \\
\text { V15PW }\end{array}$ & 22 & 0.3 & 70 & 0 & 0 & 0 & Eq. (2) \\
\hline V10PU & 22 & 0.3 & 20 & 0 & 0 & 0 & Eq. (3) and Eq. (4) \\
\hline V15PU & & & 100 & & & & \\
\hline V10U & 22 & 0.3 & 70 & 0 & 0 & 0 & Eq. (3) \\
\hline V15U & & & 10 & & & & \\
\hline Foundation & 23.5 & 0.2 & 30000 & --- & --- & --- & --- \\
\hline $\begin{array}{l}\gamma= \\
\nu= \\
\mathrm{E}=\end{array}$ & $\begin{array}{l}\text { Total Unit } \\
\text { Poisson Ra } \\
\text { Young's M }\end{array}$ & $\begin{array}{l}\text { Neight } \\
\text { io } \\
\text { dulus }\end{array}$ & & & & & \\
\hline
\end{tabular}

Three 3D DEM simulations were conducted for each column using constant internal $\phi_{\text {'sc }}^{\prime}$ of $40^{\circ}, 45^{\circ}$ and $50^{\circ}$ ( 3 for $\mathrm{V} 10 \mathrm{PW}$ and 3 for $\mathrm{V} 10 \mathrm{PU}$ ). The results of these three simulations were 
compared with the field curves and the 3 DEM results obtained considering a variation of $\phi_{\text {sc }}$ as a function of $\sigma_{r}^{\prime}$.

Two DEM simulations were conducted to examine the effects that different aggregate gradations (No.57 and 21b) have on the performance of column V10PU. Column V15PU was simulated utilizing lengths of $3.05 \mathrm{~m}$ and $4.60 \mathrm{~m}$ to determine if there was any effect on the loaddisplacement response due to an increase in the column length. The results obtained from the DEM simulations were compared with the load-displacement curves corresponding to the six baseline stone columns (W10PW, V15PW, V10PU, V15PU, V10U and V15U) as shown in the results section. For columns V10PU and V10PW, the DEM simulations were loaded to failure in order to determine the bearing capacities. The corresponding DEM load-displacement curves were compared to the extrapolated field data predicted by using the hyperbolic equations obtained from Eq. (7.3) and Eq. (7.4) (Stuedlein 2008).

The three equations used to vary $\phi_{\text {sc }}^{\prime}$ as a function of $\sigma_{r}^{\prime}$ are as follows:

$$
\begin{aligned}
& \phi_{\mathrm{sc}}^{\prime}=44^{\circ}-10^{\circ} \log \left(\frac{\sigma_{\mathrm{r}}^{\prime}}{\mathrm{P}_{\mathrm{a}}}\right) \quad \text { Well-graded aggregate (Duncan et al. 2007) } \\
& \phi_{\mathrm{sc}}^{\prime}=47^{\circ}-12.1^{\circ} \log \left(\frac{\sigma_{\mathrm{r}}^{\prime}}{\mathrm{P}_{\mathrm{a}}}\right) \quad \text { Uniformly- graded aggregate (Duncan et al. 2007) } \\
& \phi_{\mathrm{sc}}^{\prime}=47.3^{\circ}-9.6^{\circ} \log \left(\frac{\sigma_{\mathrm{r}}^{\prime}}{\mathrm{P}_{\mathrm{a}}}\right) \quad \text { Uniformly-graded aggregate (Newton 2014) }
\end{aligned}
$$

where $\sigma_{\mathrm{r}}^{\prime}=$ the effective confining pressure and $\mathrm{P}_{\mathrm{a}}=$ the atmospheric pressure. 


\section{RESULTS AND DISCUSSION}

Figure 8 compares the load-displacement curves of the stone column constructed with well-graded aggregate (V10PW) obtained using constant aggregate friction angles and while varying $\phi_{\text {sc }}^{\prime}$ with $\sigma_{\mathrm{r}}^{\prime}$. For $\phi_{\text {sc }}^{\prime}$ of $40^{\circ}$, the numerical results of the DEM simulations are close to that measured in the field for Q less than $300 \mathrm{kPa}$. However, beyond this value, the DEM curve overestimates the settlement with respect to what was observed in the field. For $\phi^{\prime}$ sc equal to $45^{\circ}$, the DEM simulation better captures the load-displacement curve for settlements less than $30 \mathrm{~mm}$, but beyond this value, the DEM curve slightly underestimates the settlement in comparison with field curve. Therefore, if the load-displacement curve for $\phi^{\prime} s c=45^{\circ}$ is extrapolated to an ultimate load condition, it would overestimate the bearing capacity in comparison with the field data. In the case of $\phi^{\prime}$ sc equal to $50^{\circ}$, the DEM curve aligns with the field curve for settlement less than 10 $\mathrm{mm}$. However, for values of settlement greater than $10 \mathrm{~mm}$, the DEM simulation notably underestimates the settlements observed in the field. The DEM curve obtained using Eq. (2) proposed by Duncan et al. (2007) for a relative density ranging from $65 \%$ to $75 \%$ is in excellent agreement with field load-displacement curve. It also matches with the DEM curve for $\phi_{\text {sc }}^{\prime}=45^{\circ}$ for Q less than $800 \mathrm{kPa}$; however, it captures the shape of the field load-displacement curve better than the DEM curve for a constant $\phi^{\prime}$ sc.

Figure 9 compares the load-displacement curves of the stone column constructed with uniformly graded aggregate (V10PU) obtained using constant internal friction angles, and while varying $\phi_{\mathrm{sc}}^{\prime}$ with $\sigma_{\mathrm{r}}^{\prime}$. For $\phi_{\mathrm{sc}}^{\prime}$ of $40^{\circ}$, the numerical results of the DEM simulation are close to that measured in the field for Q less than $400 \mathrm{kPa}$. However, beyond that value, it overestimates the settlement with respect to the field results, similar to what it was noticed for V10PW. For $\phi^{\prime}$ sc of $45^{\circ}$, the DEM simulation agrees well with the field curve at all the values of Q. 


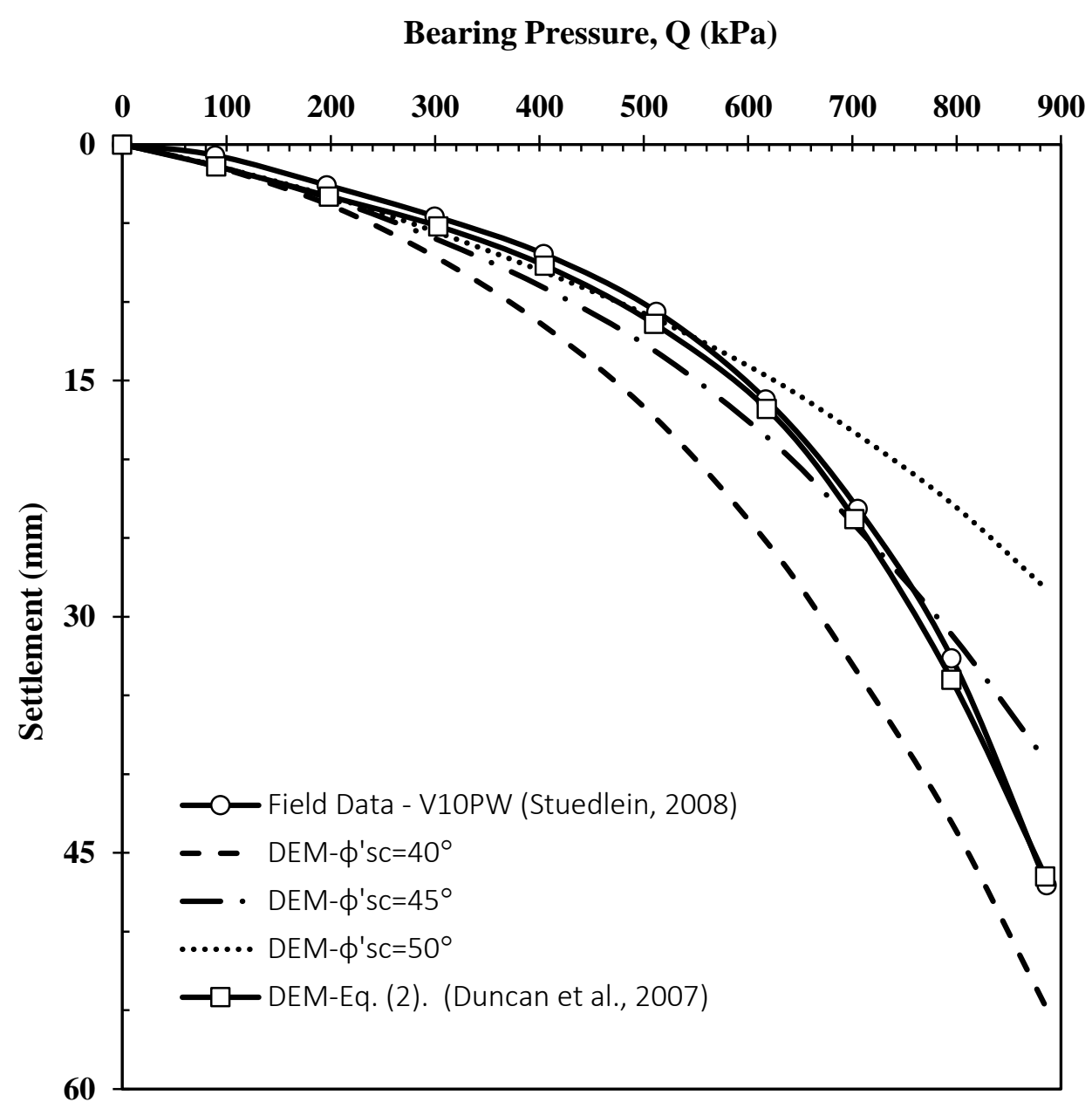

Figure 8. Comparison of the load-displacement curve corresponding to the stone column V10PW for constant friction angles $40^{\circ}, 45^{\circ}$ and $50^{\circ}$, and Eq. (2).

In the case of $\phi^{\prime}$ sc of $50^{\circ}$, the DEM curve also matches well with the field curve for settlement less than $40 \mathrm{~mm}$. However, beyond $40 \mathrm{~mm}$, the DEM simulation starts slightly underestimating the settlement observed in the field. V10PU appears to be less sensitive to the variation of $\phi^{\prime}$ sc in comparison to V10PW. For a $\phi_{\text {sc }}^{\prime}$ of $40^{\circ}$, the DEM results are conservative with respect to the field data. This behavior was observed for both types of aggregate gradation curves (V10PW and V10PU), and it agrees with the observation mentioned by McCabe et al. (2009) that using a $\phi_{\text {sc }}^{\prime}$ of $40^{\circ}$ is conservative for stone columns installed using the bottom feed method. The DEM curve obtained using Eq. (3) proposed by Duncan et al. (2007) for a relative 
density ranging from $65 \%$ to $95 \%$ aligns very well with what was observed in the field, and it is almost identical to the DEM curve for a $\phi^{\prime}$ of $45^{\circ}$.

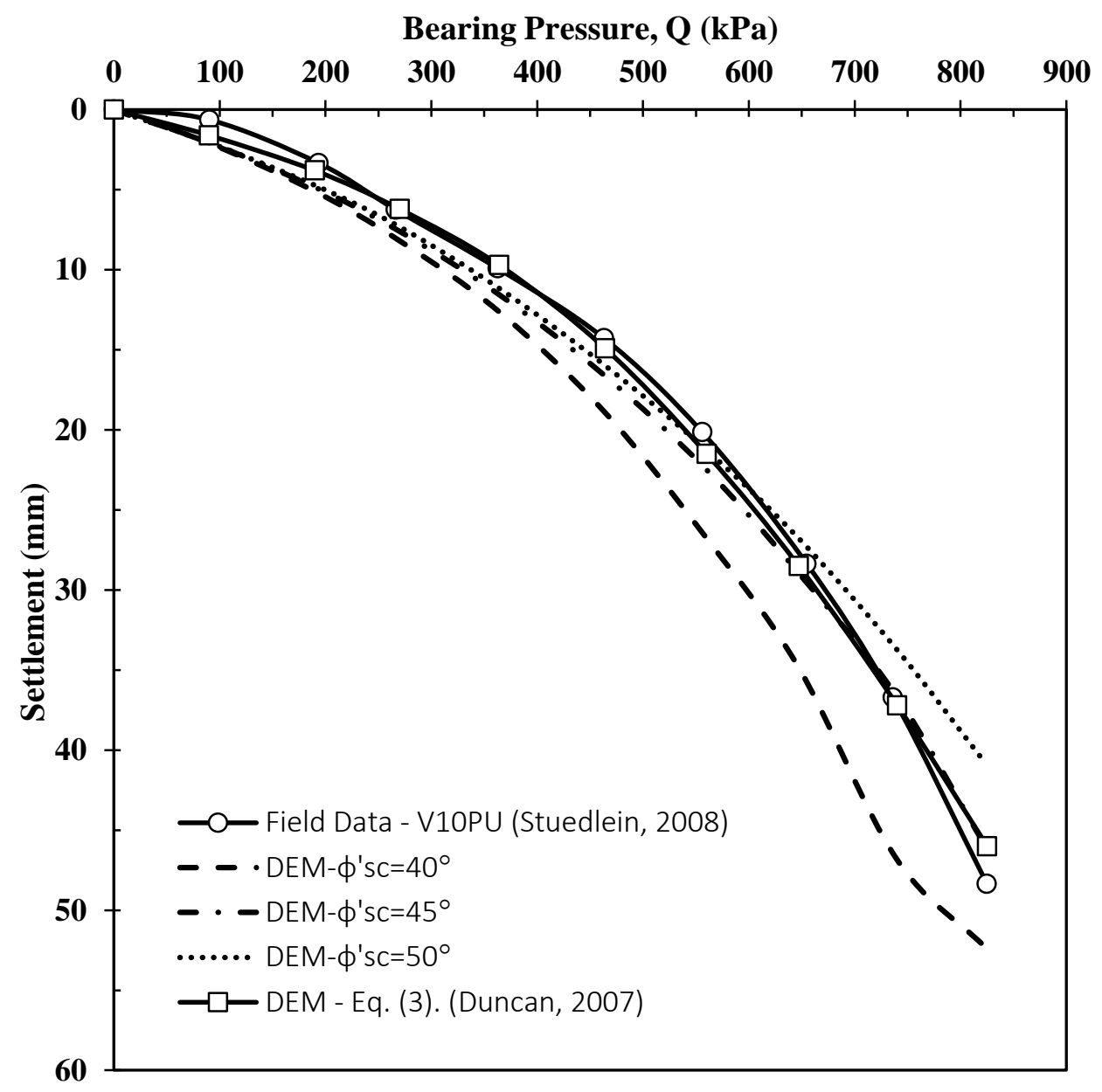

Figure 9. Comparison of the load-displacement curve corresponding to the stone column V10PU for constant friction angles $40^{\circ}, 45^{\circ}$ and $50^{\circ}$, and Eq. (3).

Figure 10 (a) compares the DEM load-displacement curve of column V10PW with the field results from Stuedlein (2008). The DEM curve is in excellent agreement with what was observed in the field for the full range of bearing pressures. Figure 10 (b) illustrates the radial displacement distribution with depth. The DEM simulation predicted a maximum radial 
displacement on the side of the column of approximately $8 \mathrm{~mm}$ at a depth around $1.30 \mathrm{~m}$. At the same depth but at a radial distance of $2 \mathrm{D}_{\mathrm{sc}}$ away from the center of the column, the radial displacement is approximately $1 \mathrm{~mm}$. The bulging zone depth $(\mathrm{h})$ is approximately $2 \mathrm{D}_{\mathrm{sc}}$, beyond which no significant radial displacement is observed. The distribution of the average $\sigma_{\mathrm{r}}^{\prime}$ with depth is illustrated in Figure 10 (c). The average $\sigma_{r}^{\prime}$ distribution also shows that $\mathrm{h}$ is approximately $2 \mathrm{D}_{\mathrm{sc}}$, which agrees with the typical range of $2 \mathrm{D}_{\mathrm{sc}}$ to $3 \mathrm{D}_{\mathrm{sc}}$. The maximum $\sigma_{\mathrm{r}}^{\prime}$ predicted by the DEM simulation is approximately $160 \mathrm{kPa}$ at a depth of $1.30 \mathrm{~m}$ for Q of $885 \mathrm{kPa}$. Almost no increase in $\sigma_{\mathrm{r}}^{\prime}$ is observed at any depth for Q lower than $300 \mathrm{kPa}$ because Q is applied only on the surface of the pier, and the column stiffness is greater than that of the surrounding soil. Therefore, most of the load is initially carried by the column, and only a small portion is transferred by shear to the adjacent matrix soil during the first load increments. The settlement distribution with depth at the center and on the edge of the column for at Q of $885 \mathrm{kPa}$ is presented in Figure 10 (d). A maximum settlement of $50 \mathrm{~mm}$ was predicted at the top of the column, similar to what was observed in the field. The settlement is uniform along the cross section of the pier at the top of the column; however, it differs slightly for depths less than $2 \mathrm{D}_{\text {sc }}$. The displacement at the bottom of the column is around $2 \mathrm{~mm}$, which shows that most of the Q is radially distributed at the bulging zone depth, and only small portion is transferred by end bearing.

Figure 11 (a) compares the DEM load-displacement response of column V15PW with the field results. Similar to V10PW, the DEM curve is in excellent agreement with the results measured in the field by Stuedlein (2008) at all applied pressures. Figure 11 (b) shows the radial displacement distribution around the column with depth. The radial displacement is identical to that obtained for column V10PW. The average $\sigma_{r}^{\prime}$ distribution with depth is illustrated in Figure 
11 (c). For a $\mathrm{Q}$ of $895 \mathrm{kPa}$, the maximum $\sigma_{\mathrm{r}}^{\prime}$ estimated by the DEM simulation is approximately $160 \mathrm{kPa}$ at a depth of $1.30 \mathrm{~m}$, which represents a $\sigma_{\mathrm{r}}^{\prime}$ increase of approximately $120 \mathrm{kPa}$ with respect to the initial $\sigma_{r}^{\prime}$. If this $\sigma_{r}^{\prime}$ increase is divided by the average $s_{u}$ corresponding to the bulging zone length $(49 \mathrm{kPa})$, the cavity expansion factor would be 2.5 . This value differs from the $\mathrm{k}_{\mathrm{p}}$ of 4 recommended by Hughes et al. (1975). Based on the equation proposed by Stuedlein and Holtz (2013), for a $\mathrm{s}_{\mathrm{u}}$ of $49 \mathrm{kPa}, \mathrm{k}_{\mathrm{p}}$ is 2.9 , which is closer to the estimated $\mathrm{k}_{\mathrm{p}}$ for the DEM simulation. It is important to highlight that the factors used by Hughes et al. (1975) and Stuedlein and Holtz (2013) are based on the ultimate load condition. However, Q $=895 \mathrm{kPa}$ is not the bearing pressure of column V15PW; therefore, $\sigma_{\mathrm{r}}^{\prime}$ could increase at the failure condition providing a higher $\mathrm{k}_{\mathrm{p}}$. The computed $\phi_{\mathrm{sc}}^{\prime}$ corresponding to the maximum $\sigma_{\mathrm{r}}^{\prime}$ is approximately $42^{\circ}$. Using this value in Eq. (1) provides a h equal to $2 \cdot 2 \mathrm{D}_{\mathrm{sc}}$, which is very close to what was obtained from the DEM simulation for columns V10PW and V15PW. The settlement distribution with depth at the center and on the edge of the column for a Q of $895 \mathrm{kPa}$ is illustrated in Figure 11 (d). Even when the column V15PW is $1.50 \mathrm{~m}$ longer than the column V10PW, no differences in the load-displacement curves are observed in the DEM results. This agrees with what was reported by Stuedlein et al. (2012) that the length of the column does not appear to affect the performance of the columns constructed using well-graded granular material. 


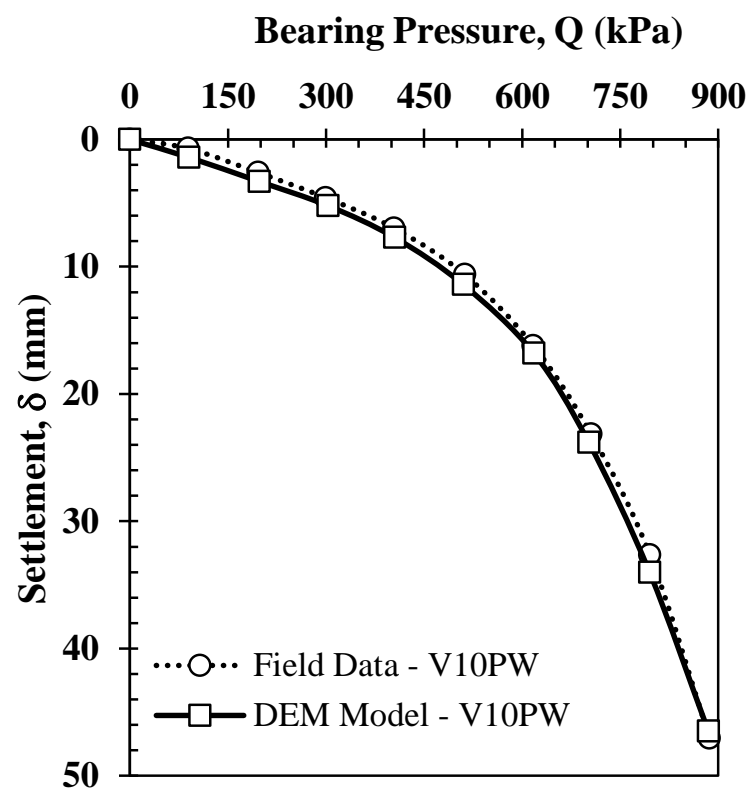

(a)

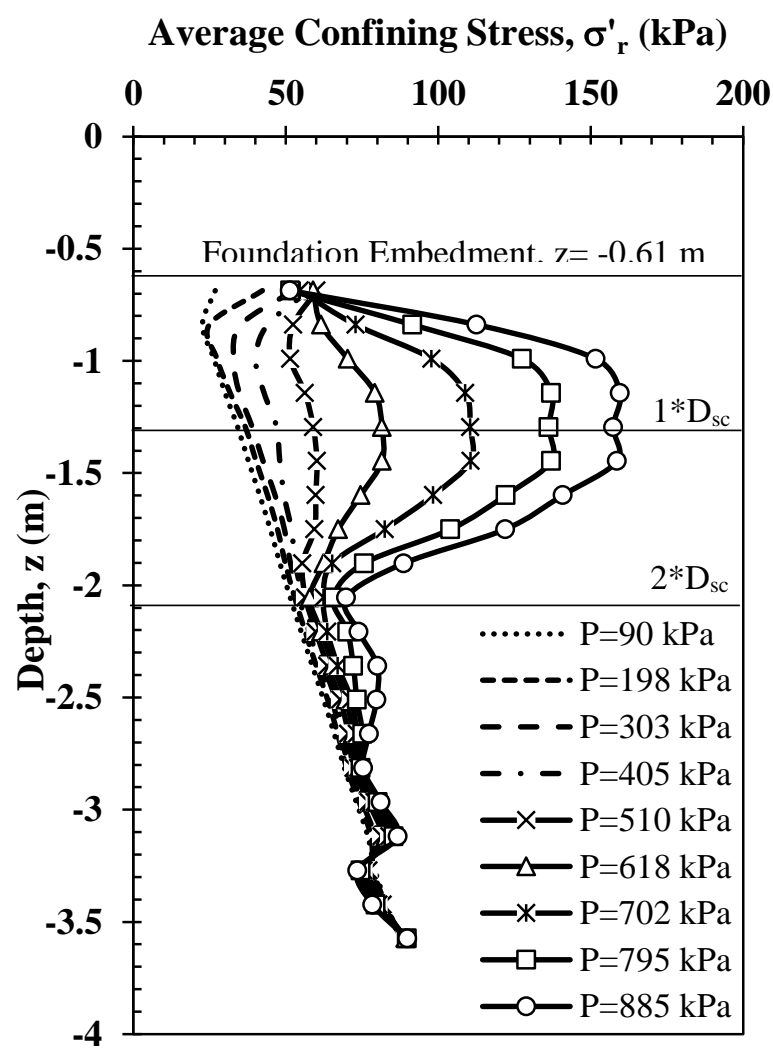

(c)

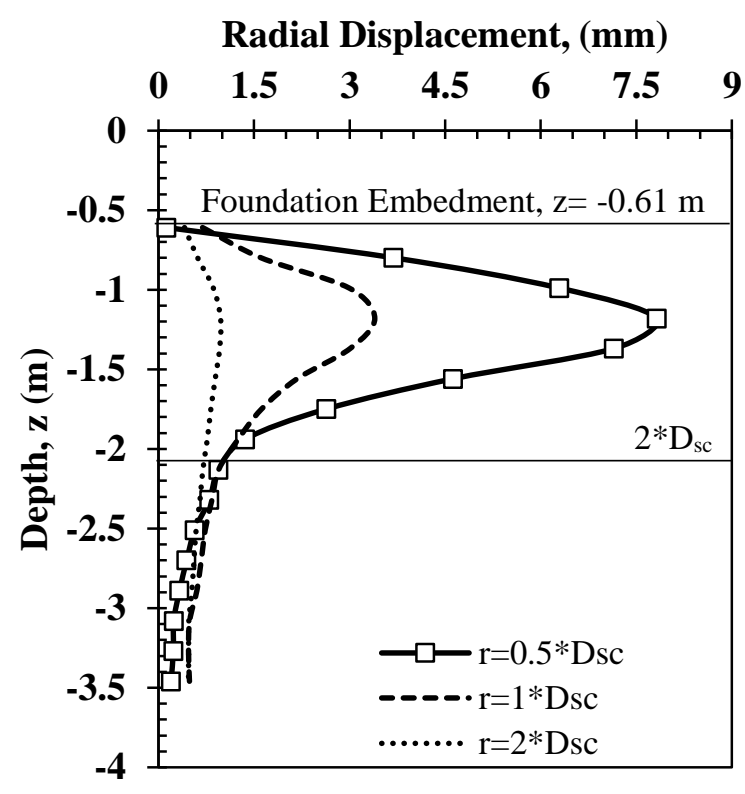

(b)

Settlement, $\delta(\mathbf{m m})$

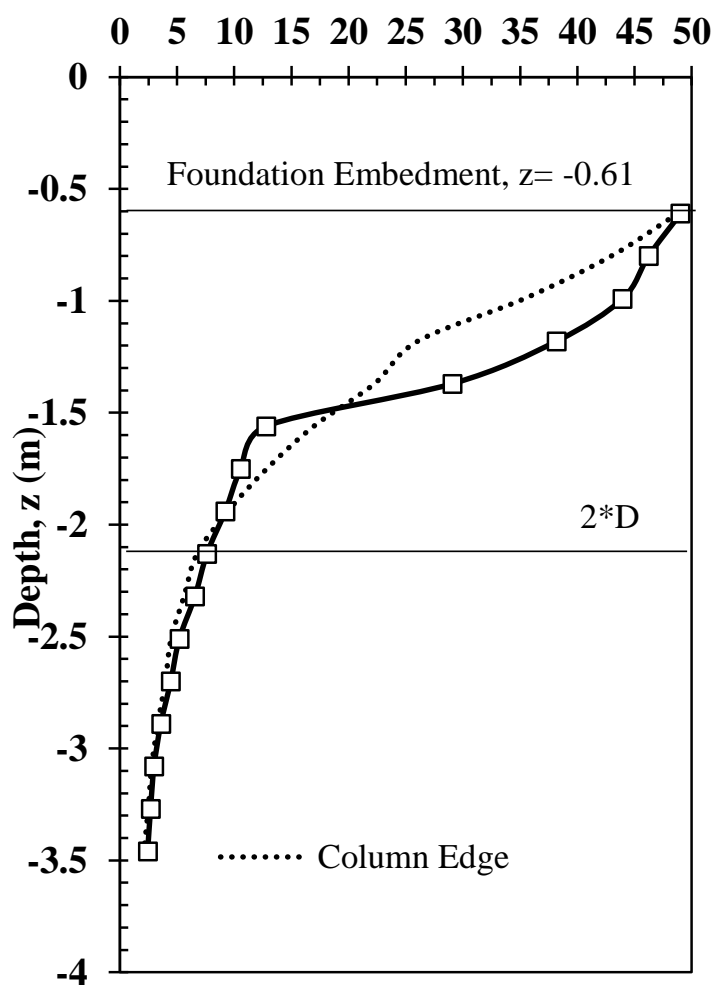

(d)

Figure 10. DEM Results for V10PW. (a) Comparison of the DEM load-displacement curve with field results, (b) Radial displacement, (c) Average confining stress distribution with depth, (d) Settlement distribution with depth for $\mathrm{Q}=885 \mathrm{kPa}$. 


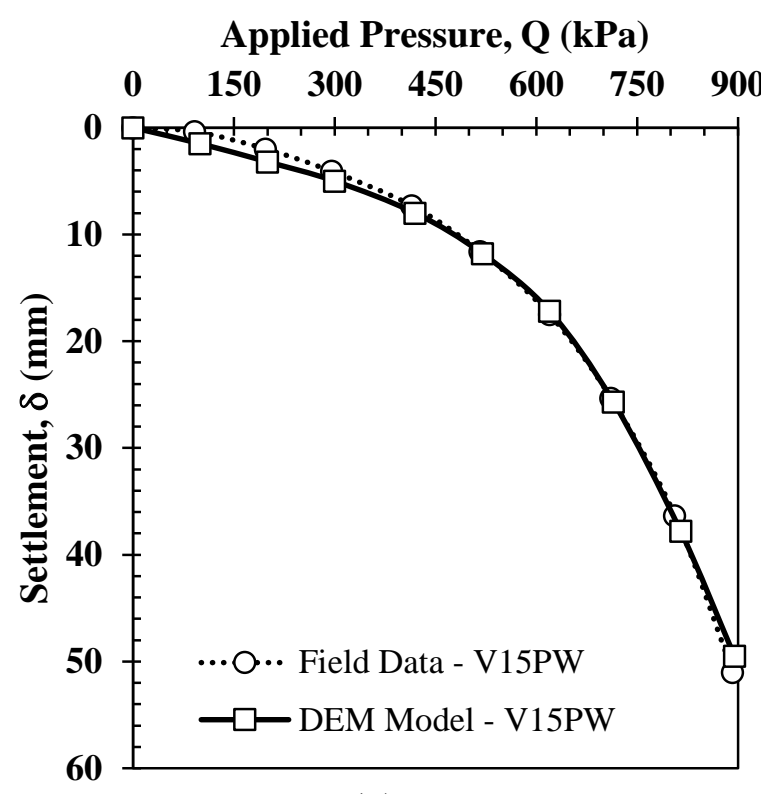

(a)

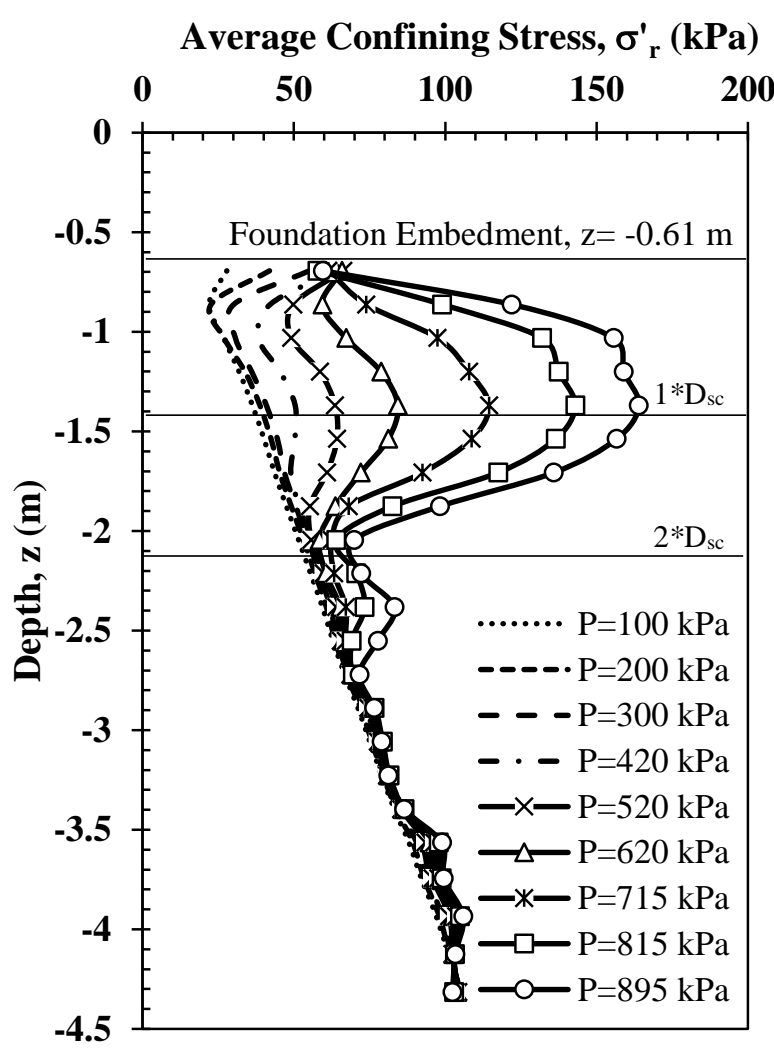

(c)

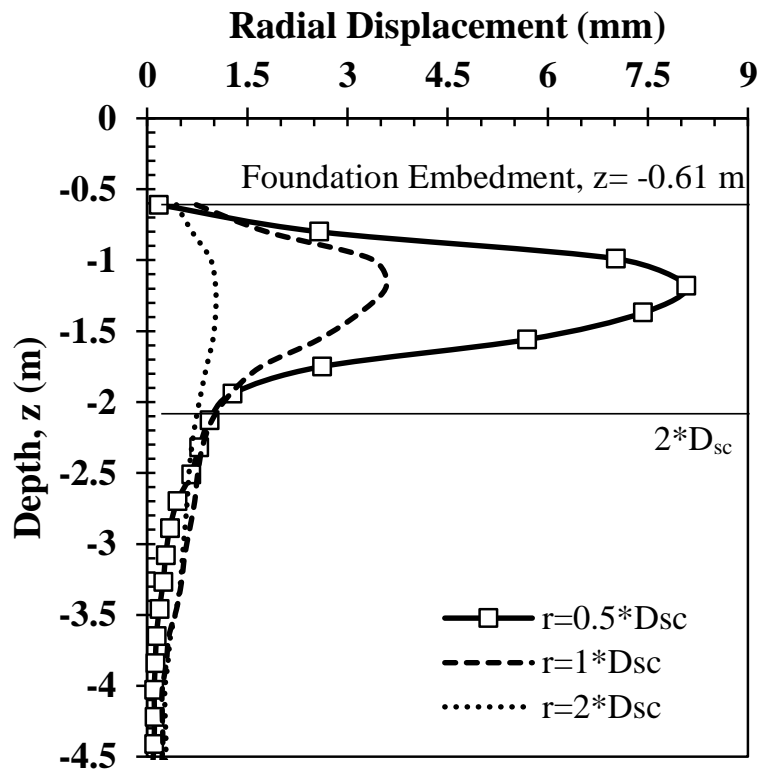

(b)

Settlement, $\delta(\mathrm{mm})$

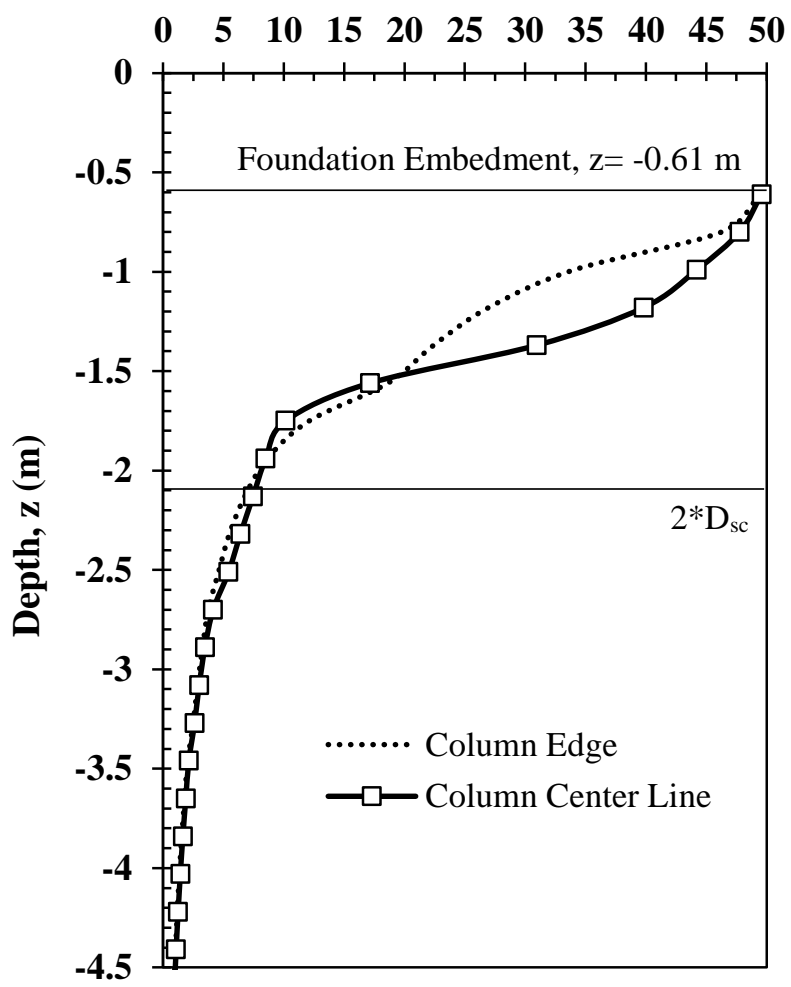

(d)

Figure 11. DEM Results for V15PW. (a) Comparison of the DEM load-displacement curve with field data, (b) Radial displacement, (c) Average confining stress distribution with depth, (d) Settlement distribution with depth for $\mathrm{Q}=895 \mathrm{kPa}$. 
Figure 12 (a) compares the DEM load-displacement curves of column V10PU with the field results from (Stuedlein, 2008). Similar to the columns built with well-graded aggregates, the DEM curve matches well with what was observed in the field for all the bearing pressures. Figure 12 (b) illustrates the radial displacement distribution with depth. The DEM simulation predicted a maximum radial displacement on the side of the column of approximately $2.5 \mathrm{~mm}$ at a depth of approximately $1.20 \mathrm{~m}$ which is $69 \%$ smaller than the $8.0 \mathrm{~mm}$ obtained for the wellgraded aggregate columns V10PW and V15PW. The bulging zone depth is defined as $2.5 \mathrm{D}_{\text {sc. }}$. The distribution of the average $\sigma_{\mathrm{r}}^{\prime}$ with depth is illustrated in Figure 12 (c). The average $\sigma_{\mathrm{r}}^{\prime}$ distribution also shows that $\mathrm{h}$ is approximately $2.5 \mathrm{D}_{\mathrm{sc}}$, which agrees within the typical range of $2 D_{\text {sc }}$ to $3 D_{\text {sc. }}$ The average $\sigma_{r}^{\prime}$ distribution is different from the well-graded aggregate columns even though the radial distribution still shows bulging. For column V10PU, the replacement area $\left(A_{r}\right)$ is $97 \%$, and a percentage of the applied pressure is transferred to the surrounding soil underneath the footing causing an increase in the vertical and confining stresses at the top of the column as shown Figure 12 (c). The maximum $\sigma_{\mathrm{r}}^{\prime}$ predicted by the DEM simulation is approximately $150 \mathrm{kPa}$ at the top of the column. Almost no increase in the $\sigma_{\mathrm{r}}^{\prime}$ is observed at depths greater than $0.61 \mathrm{~m}$ for $\mathrm{Q}$ lower than $364 \mathrm{kPa}$. The settlement distribution with depth at the center and at the edge of the column for the $\mathrm{Q}$ of $825 \mathrm{kPa}$ is presented in Figure $12(\mathrm{~d})$. A maximum settlement of $45 \mathrm{~mm}$ was predicted at the top of the column, similar to what was observed in the field; however, the initial Young's modulus of this column is 3 times less than the columns V10PW and V15PW. Because of the rigidity of the concrete footing, the settlement appears to be uniform along the cross section of the pier at the top of the column. The displacement at the bottom of the column is approximately $2 \mathrm{~mm}$ showing that most of Q is transferred to the firm stratum similar to what is observed for the well-graded aggregate 
columns. Figure 13 (a) compares the DEM load-displacement response of column V15PU. The DEM simulation provides a good representation of the load-displacement response with respect to the results obtained in the field by (Stuedlein, 2008). The DEM simulation slightly overestimates the settlement for bearing pressures less than $450 \mathrm{kPa}$; however, beyond this value, it agrees well with the field data. This column provides a stiffer load-displacement response than the other columns modeled in this study. This could be caused by the compaction method or column length. Figure 13 (b) shows the radial displacement of the column with depth. The maximum radial displacement $(1.8 \mathrm{~mm})$ is $77 \%$ lower than those obtained for the well-graded aggregate columns. Because of the high column stiffness, higher pressures would be needed to fail the column in bulging. The average $\sigma_{r}^{\prime}$ distribution with depth is illustrated in Figure 13 (c). It is observed that the bulging length is around $2 \mathrm{D}_{\text {sc. }}$. The $\mathrm{A}_{\mathrm{r}}$ of this column is $97 \%$, and the average $\sigma_{r}^{\prime}$ distributions are also affected at the top of the column as a result of the increase in the vertical and horizontal stress induced by the $\mathrm{Q}$ on the footing. For a $\mathrm{Q}$ of $840 \mathrm{kPa}$, the maximum $\sigma_{\mathrm{r}}^{\prime}$ estimated by the DEM simulation is approximately $100 \mathrm{kPa}$ at a depth of $1.50 \mathrm{~m}$, which represents a $\sigma_{\mathrm{r}}^{\prime}$ increase of approximately $60 \mathrm{kPa}$ with respect to the initial $\sigma_{\mathrm{r}}^{\prime}$. This does not represent a significant reduction in $\phi_{\text {sc }}^{\prime}$ which differs from what is observed for the wellgraded aggregate columns. The settlement distribution with depth at the center and on the edge of the foundation for Q of $845 \mathrm{kPa}$ is shown in Figure 13 (d). The maximum settlement observed in the field and estimated by the DEM model is half of that of column V10PU for similar Q values. These columns were constructed using the same gradation; however, V15PU is $1.50 \mathrm{~m}$ longer than column V10PU. Therefore, the length of the column could be a factor affecting the load-displacement response. 


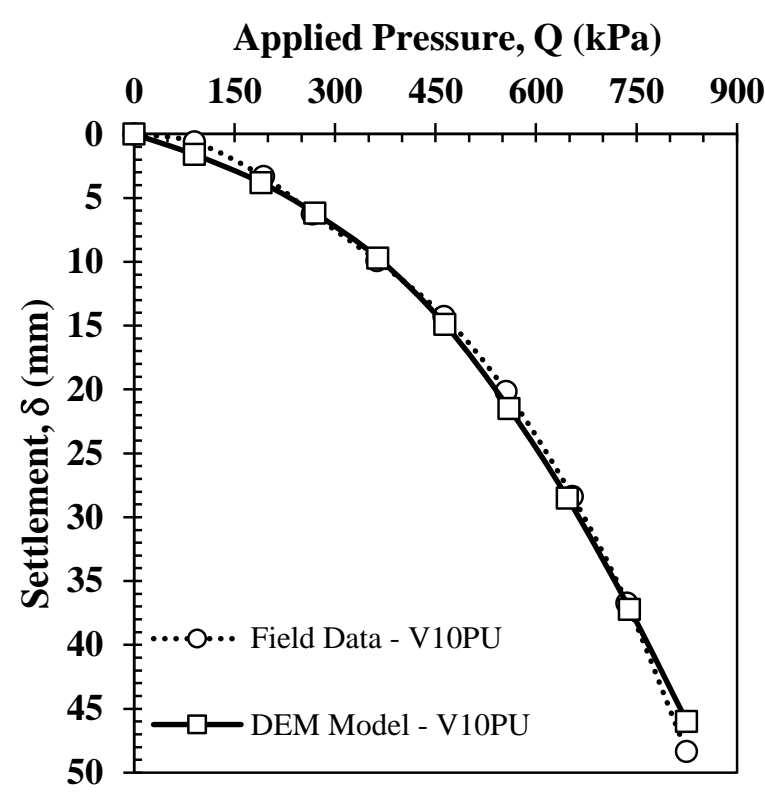

(a)

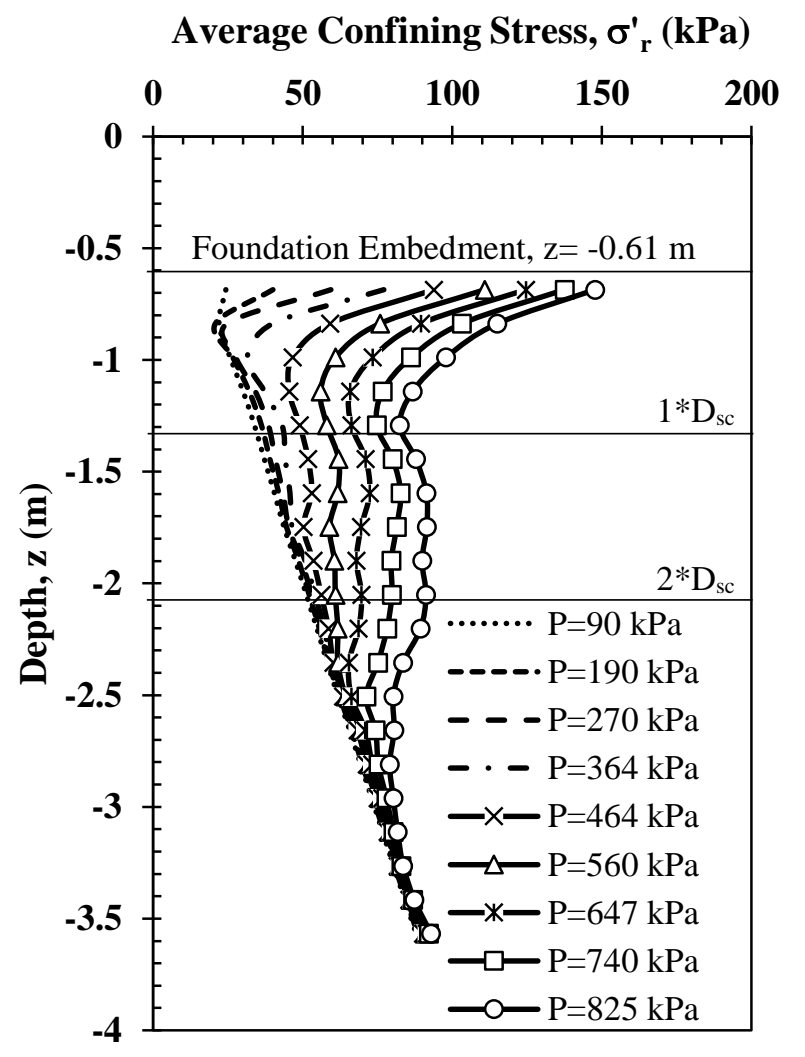

(c)

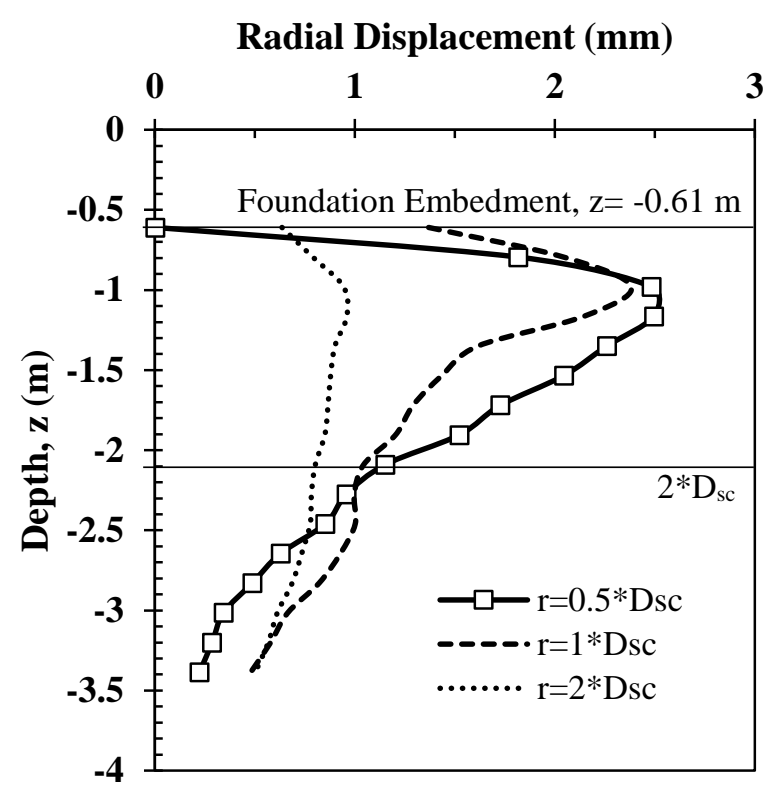

(b)

Settlement, $\delta(\mathbf{m m})$

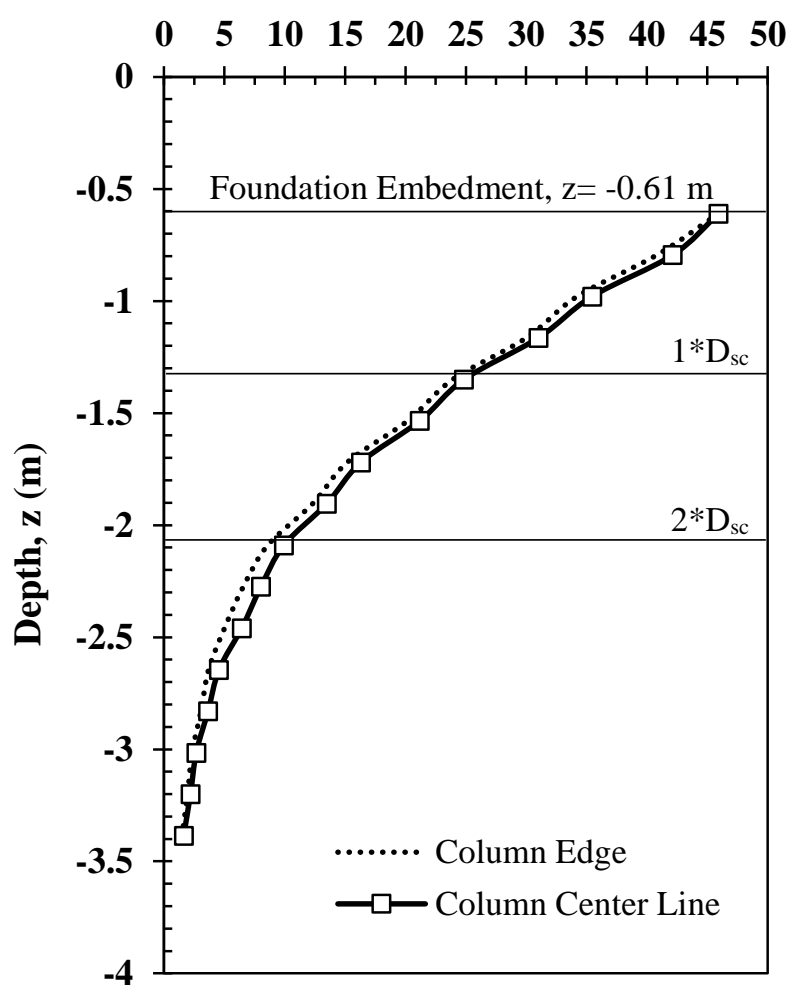

(d)

Figure 12. DEM Results for V10PU. (a) Comparison of the DEM load-displacement curve with field data, (b) Radial displacement, (c) Average confining stress distribution with depth, (d) Settlement distribution with depth for $\mathrm{Q}=825 \mathrm{kPa}$. 


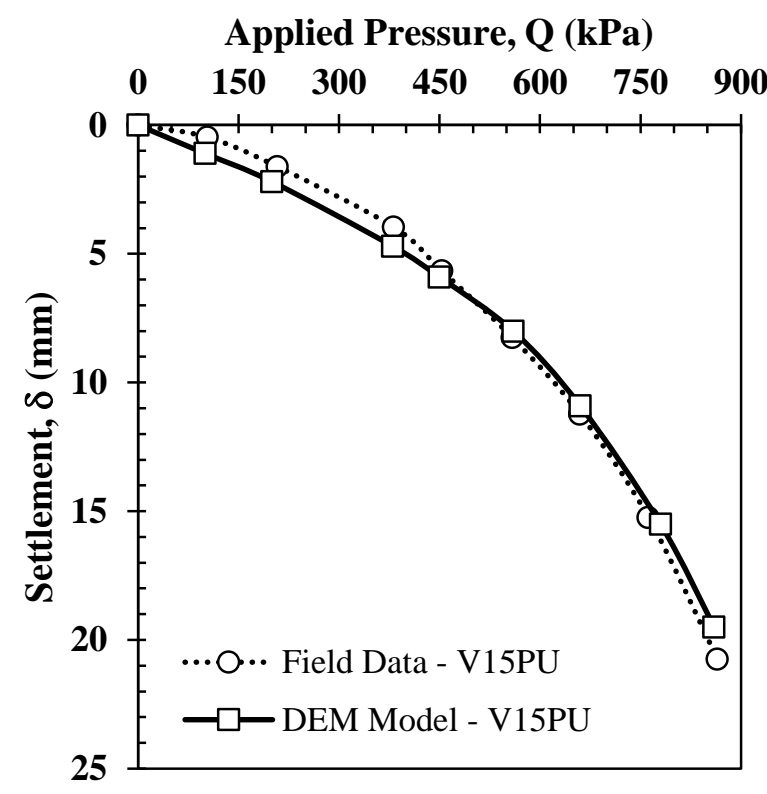

(a)

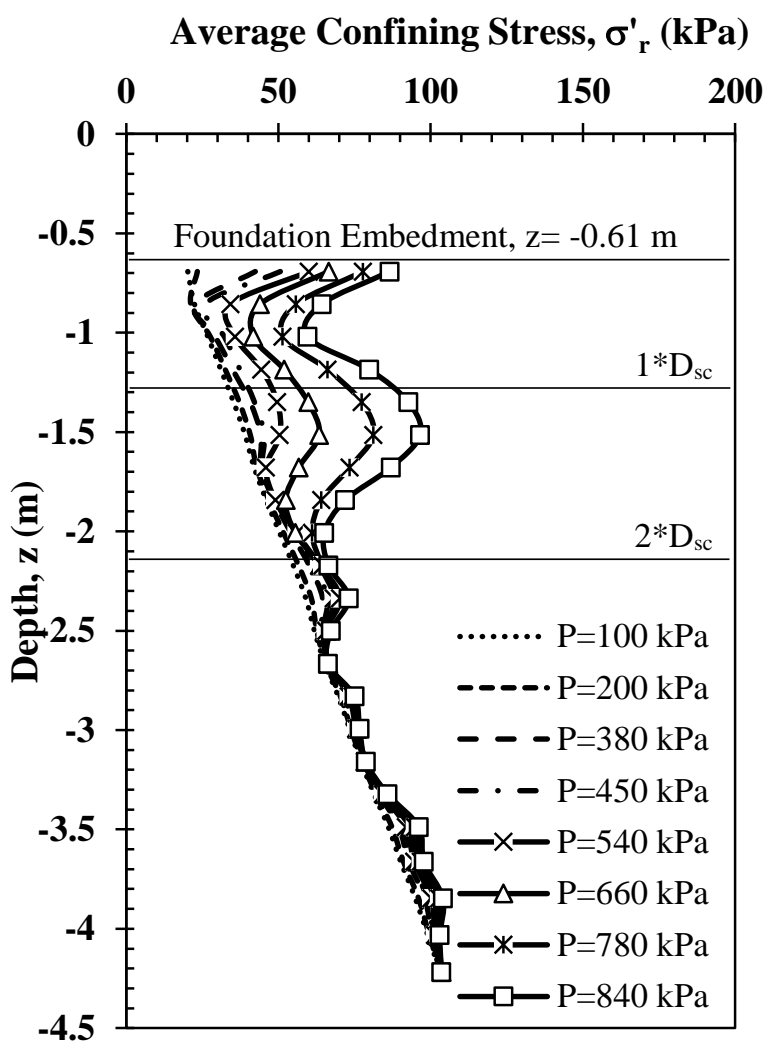

(c)

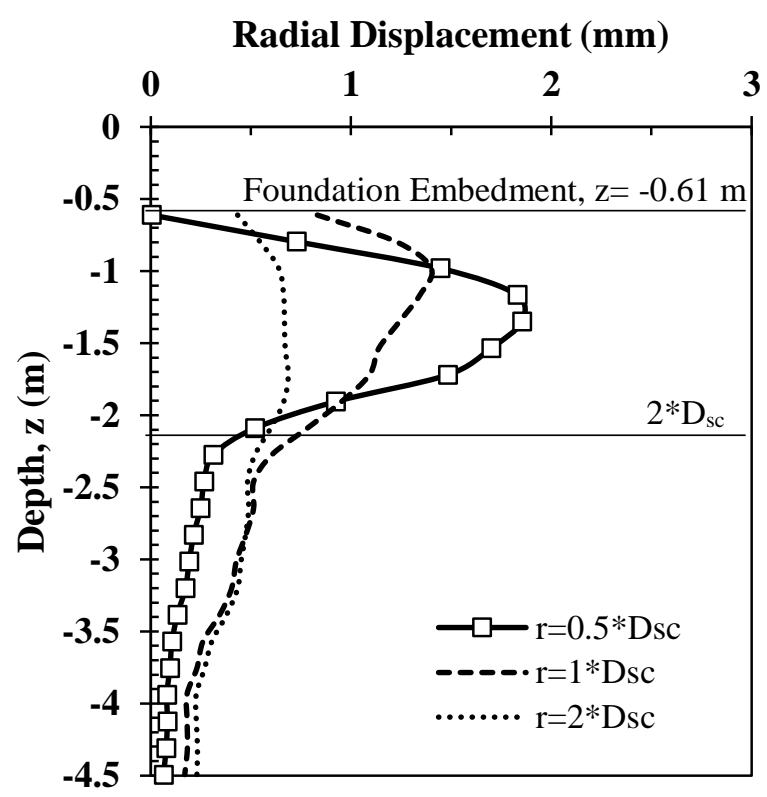

(b)

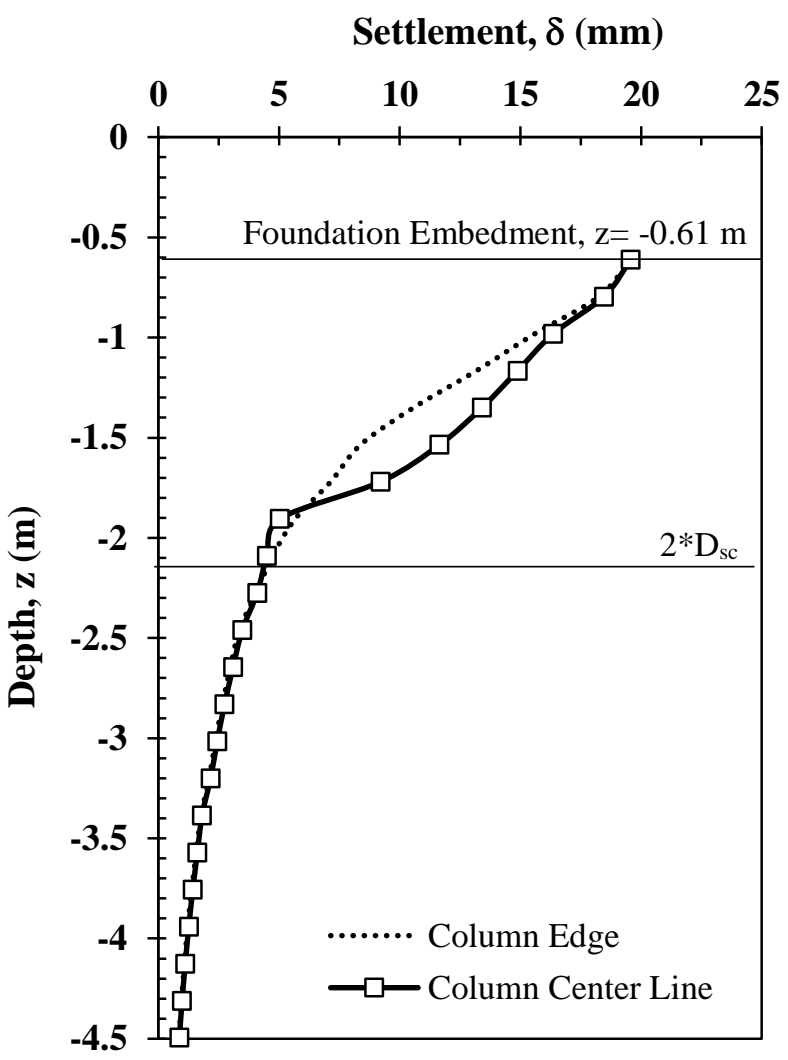

(d)

Figure 13. DEM Results for V15PU. (a) Comparison of the DEM load-displacement curve with field data, (b) Radial displacement, (c) Average confining stress distribution with depth, (d) Settlement distribution with depth for $\mathrm{Q}=840 \mathrm{kPa}$. 
Figure 14 (a) compares the DEM load displacement response of the column (V10U) with the field results from (Stuedlein, 2008). The DEM curve captures the field load-displacement curve for all the applied pressures. Figure 14 (b) illustrates the radial displacement distribution with depth. The DEM simulation shows a maximum radial displacement on the side of the column of approximately $4.0 \mathrm{~mm}$ at a depth of around $1.30 \mathrm{~m}$. At the same depth, but at a radial distance of $2 \mathrm{D}_{\mathrm{sc}}$ away from the center of the column, the lateral displacement is around $0.5 \mathrm{~mm}$. Therefore, the bulging zone influence is negligible for radial distances greater than $2 \mathrm{D}_{\mathrm{sc}}$ from the column center. The bulging zone depth is defined as $2 \mathrm{D}_{\mathrm{sc}}$. The distribution of the average $\sigma_{\mathrm{r}}^{\prime}$ with depth is illustrated in Figure 14 (c). The average $\sigma_{r}^{\prime}$ distribution also shows that $\mathrm{h}$ is approximately $2 \mathrm{D}_{\mathrm{sc}}$, which is in accordance with what was predicted for the other columns and Eq. (1). Because the $A_{r}$ of column V10U is $93 \%$, a higher percentage of the applied pressure is transmitted to the surrounding soil beneath the foundation causing an increase in the confining stress within the stone column as shown in Figure 14 (c).

The maximum $\sigma_{\mathrm{r}}^{\prime}$ observed for the DEM simulation is approximately $125 \mathrm{kPa}$ at the top of the column. Almost no increase in the $\sigma_{\mathrm{r}}^{\prime}$ is observed at depths greater than $2 \mathrm{D}_{\mathrm{sc}}$ for any $\mathrm{Q}$. The settlement distribution with depth at the center and on the edge of the column for the Q of $810 \mathrm{kPa}$ is presented in Figure 14 (d). A maximum settlement of $36 \mathrm{~mm}$ was estimated at the top of the column, similar to what was measured in the field. However, the initial stiffness of this column is between columns V10PU and V15PU. Since these three columns were built with the same gradation, the difference in the stiffness is likely caused by the either the column length or by the installation methods rather than gradation effects.

Figure 15 (a) compares the DEM load-displacement response of column V15U. Overall, the DEM simulation agrees well with the results obtained in the field. For Q greater than 540 
$\mathrm{kPa}$, the DEM curve slightly underestimates the settlement observed in the field. This column provides a less stiff load-displacement response than the other columns modeled in this study. This could be caused by some soil disturbance generated at the site during the testing program as reported by Stuedlein (2008). Figure 15 (b) shows the radial displacement of the column with depth. The maximum radial displacement is $4.5 \mathrm{~mm}$, which is very similar to that predicted for V10U even though V15U is $50 \%$ less stiff based on their initial Young's modulus comparison. The average $\sigma_{\mathrm{r}}^{\prime}$ distribution with depth is illustrated in Figure 15 (c). For this column, the bulging zone length is around $3 \mathrm{D}_{\mathrm{sc}}$. The average $\sigma_{\mathrm{r}}^{\prime}$ distribution for this column is more variable with depth than for columns V10PU, V15PU and V10U as a consequence of the lower su profile. For the $\mathrm{Q}$ of $730 \mathrm{kPa}$, the maximum $\sigma_{\mathrm{r}}^{\prime}$ predicted by the $\mathrm{DEM}$ model is approximately $150 \mathrm{kPa}$ at the top of the column, which represents a $\sigma_{\mathrm{r}}^{\prime}$ increase of approximately $130 \mathrm{kPa}$ with respect to the initial $\sigma_{\mathrm{r}}^{\prime}$.

The settlement distribution with depth at the center and on the edge of the column for Q of $845 \mathrm{kPa}$ is shown in Figure 15 (d). The maximum settlement $(95 \mathrm{~mm})$ observed in the field and DEM simulation is almost double of that obtained for column V10PU. Based on this poor column resistance performance, this column does not provide any improvement to the unreinforced soil because of the soil disturbance. 


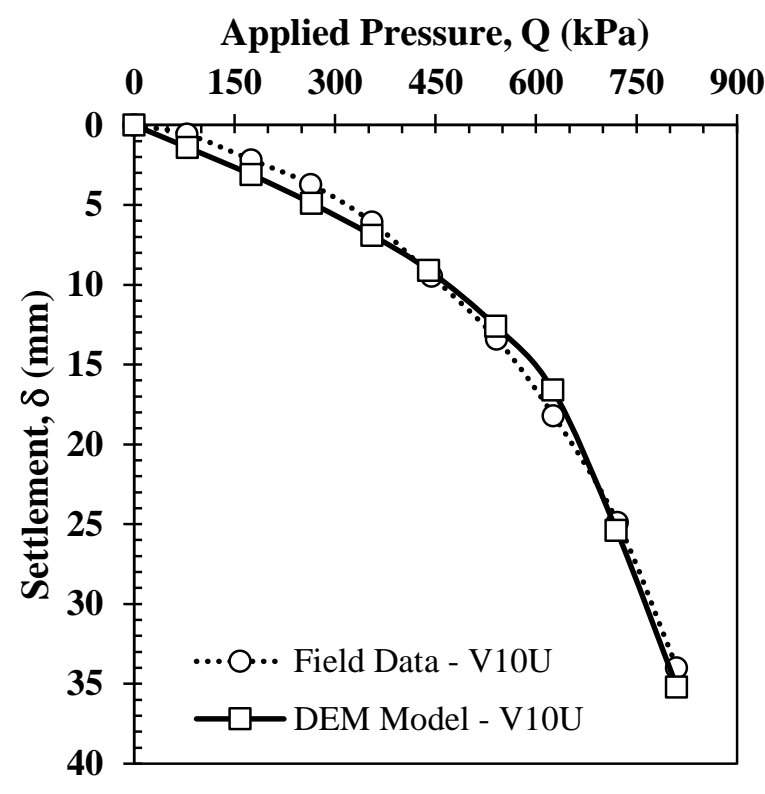

(a)

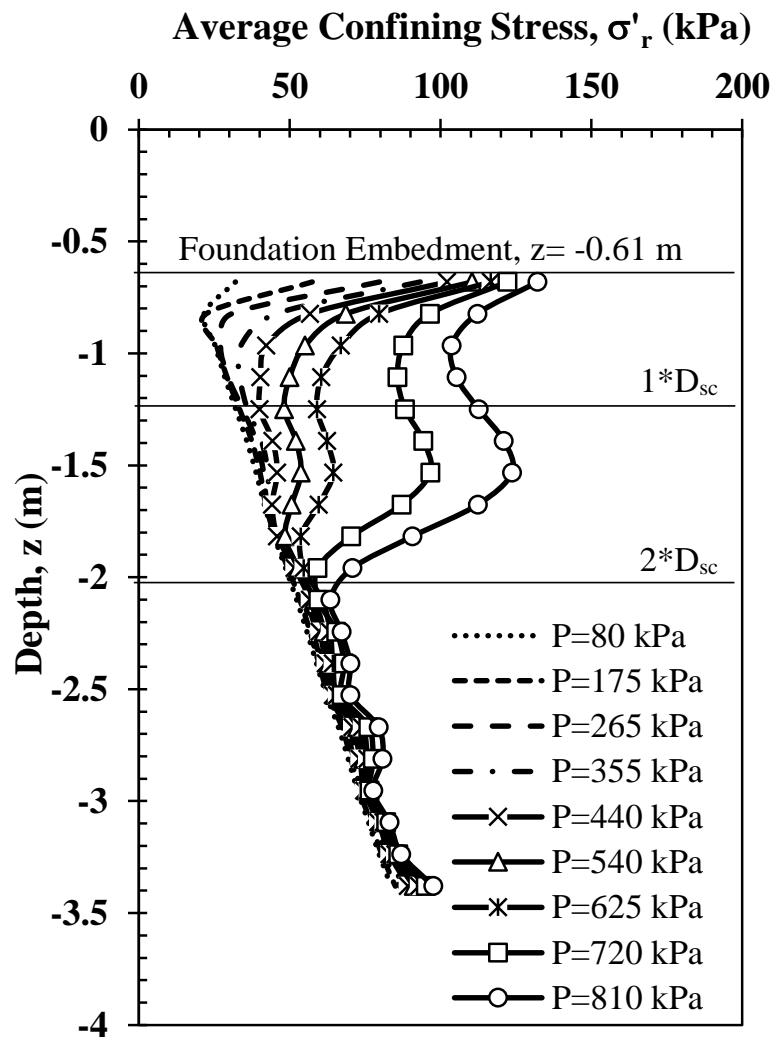

(c)

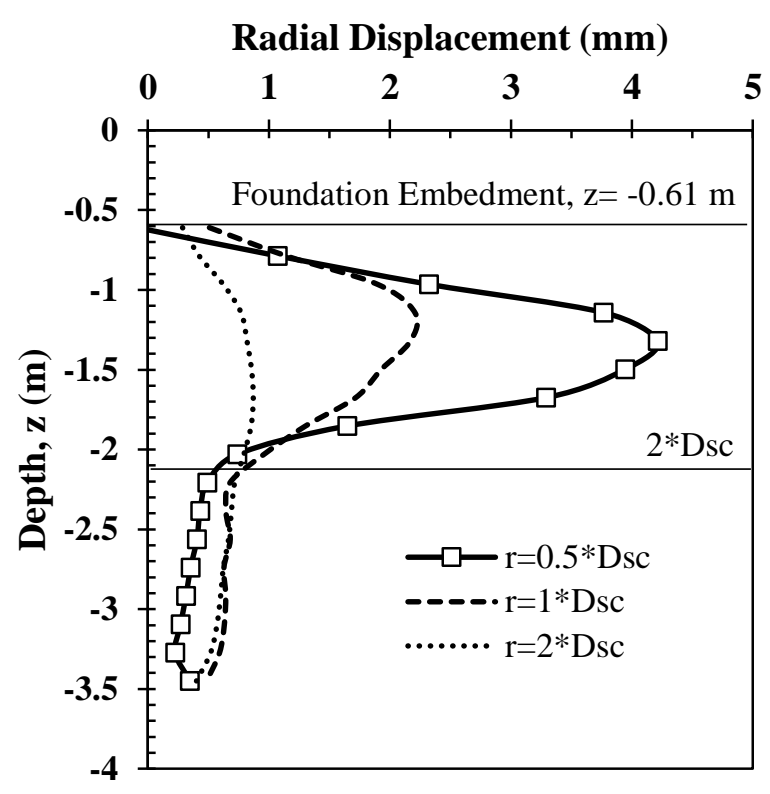

(b)

Settlement, $\delta(\mathbf{m m})$

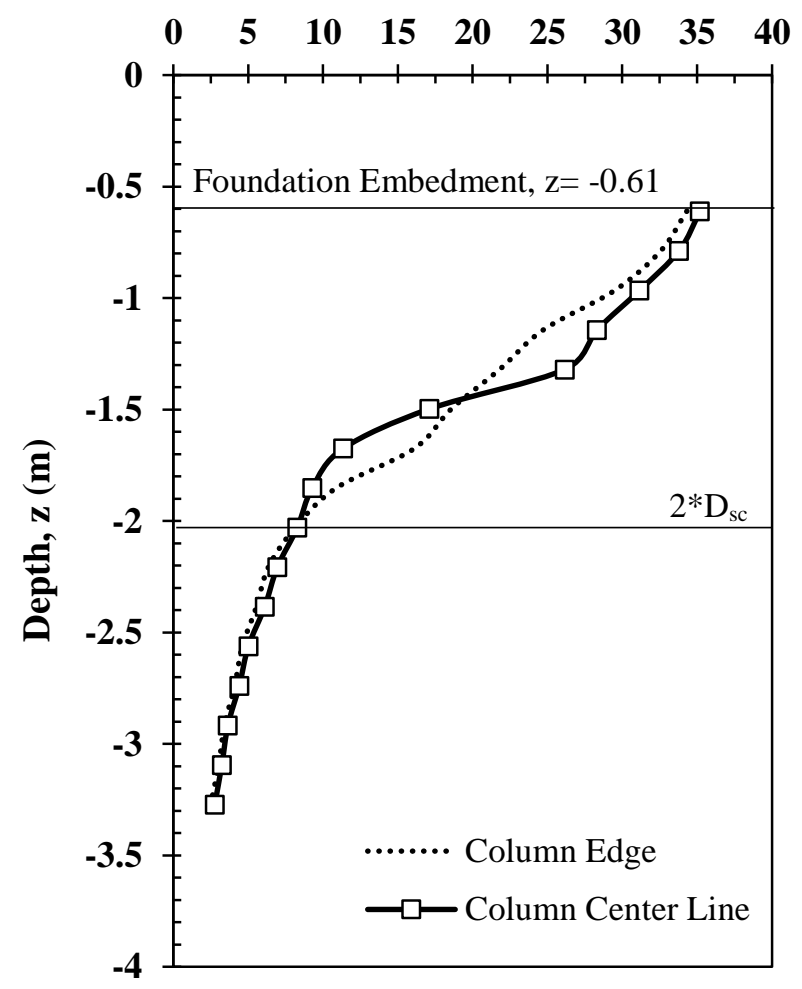

(d)

Figure 14. DEM Results for V10U. (a) Comparison of the DEM load-displacement curve with field data, (b) Radial displacement, (c) Average confining stress distribution with depth, (d) Settlement distribution with depth for $\mathrm{Q}=810 \mathrm{kPa}$. 


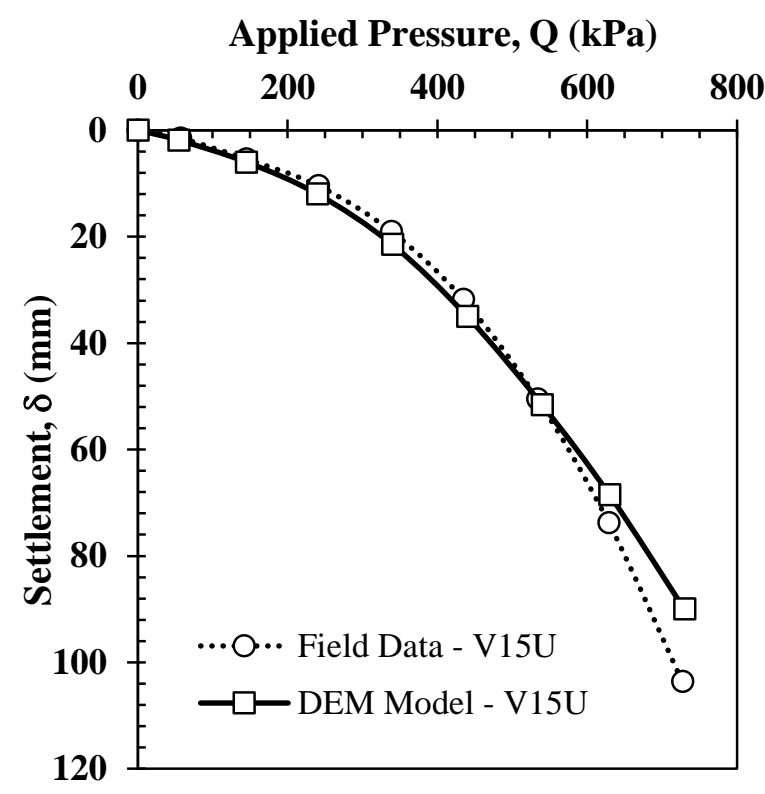

(a)

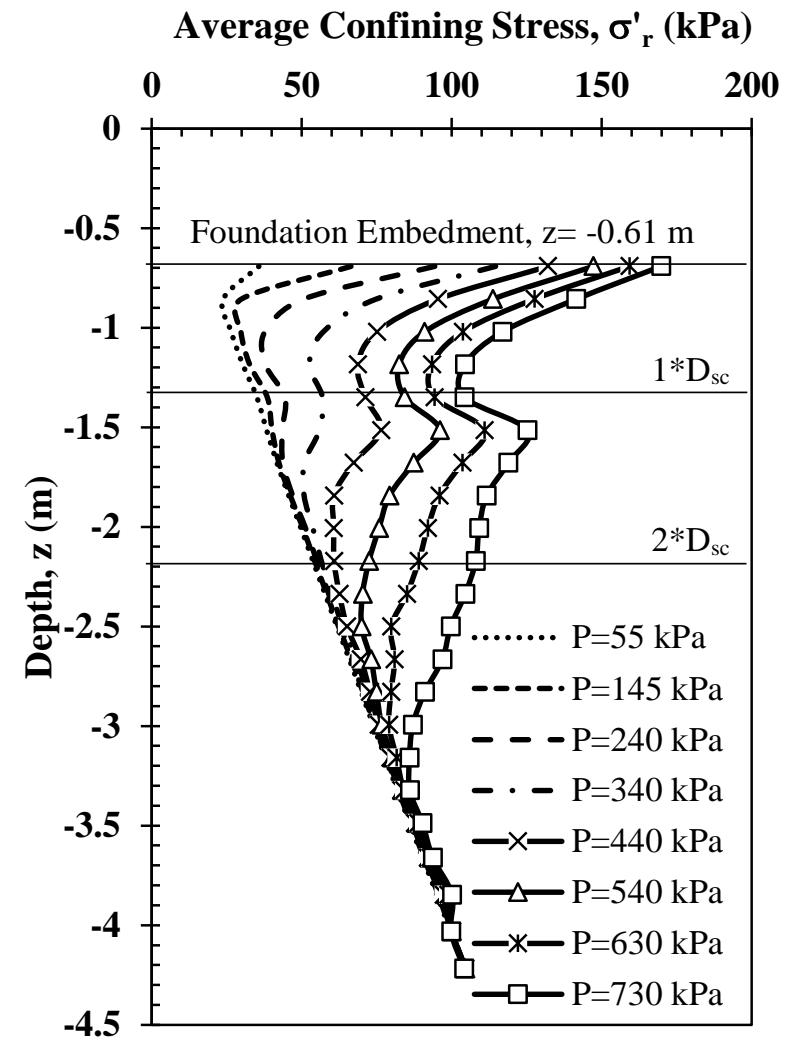

(c)

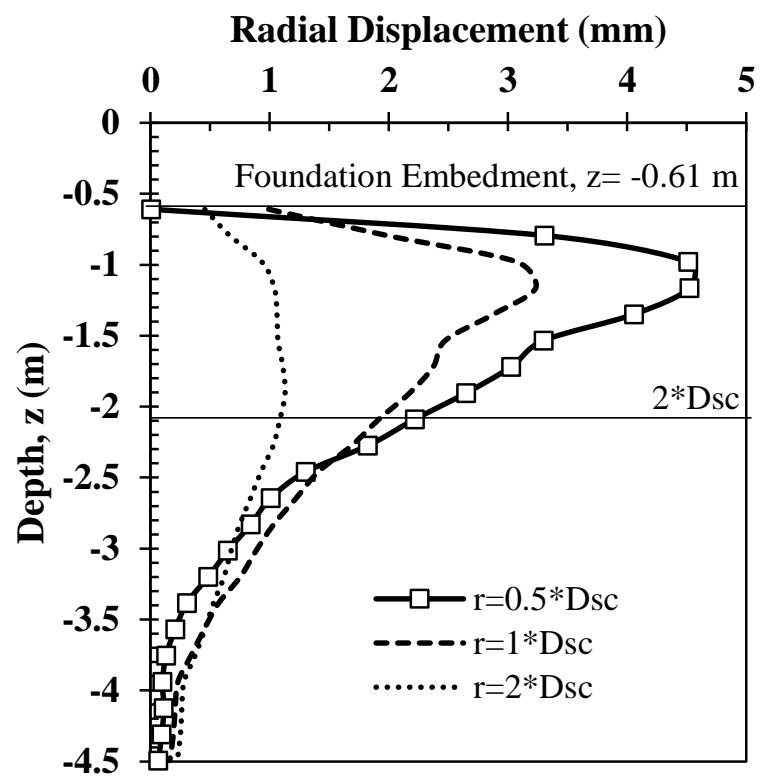

(b)

Settlement, $\delta(\mathbf{m m})$

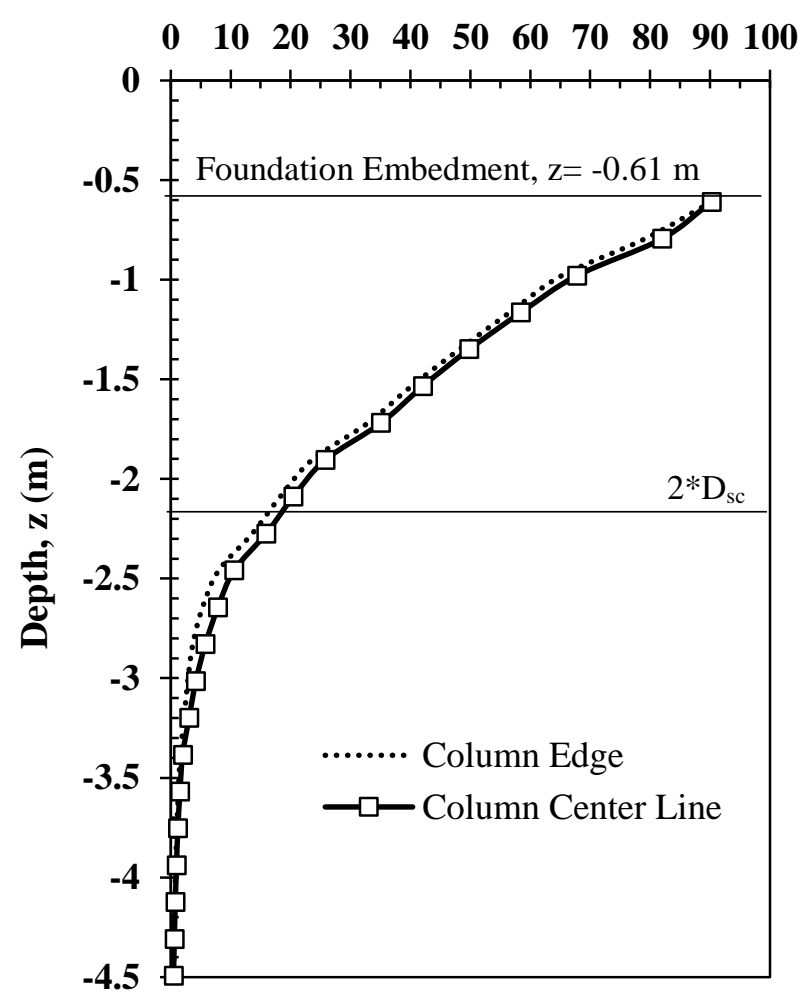

(d)

Figure 15. DEM Results for V15U. (a) Comparison of the DEM load-displacement curve with field data, (b) Radial displacement, (c) Average confining stress distribution with depth, (d) Settlement distribution with depth for $\mathrm{Q}=840 \mathrm{kPa}$. 
Figure 16 (a) shows a comparison of the full load-displacement curves of the stone column constructed with well-graded aggregate (V10PW) obtained while varying $\phi_{\text {sc }}^{\prime}$ as a function of $\sigma_{r}^{\prime}$. The DEM curve obtained using Eq. (2) proposed by Duncan et al. (2007) for a relative density ranging from $65 \%$ to $75 \%$ is in excellent agreement with the extrapolated field curve obtained using the hyperbolic Eq. (7.4) from Stuedlein (2008) for settlement less than $75 \mathrm{~mm}$. Beyond this value, the DEM curve shifts to the right with respect to the extrapolated hyperbolic curve. The predicted bearing capacity obtained using the hyperbolic Eq. (7.4) for the pier V10PW is approximately $1160 \mathrm{kPa}$, whereas based on the DEM curve, it is $1275 \mathrm{kPa}$. This represents an error of $9 \%$ in comparison to the extrapolated field curve.

Figure 16 (b) compares the full load-displacement curves of the stone column constructed with uniformly-graded aggregate (V10PU) computed by varying $\phi_{\mathrm{sc}}^{\prime}$ with $\sigma_{\mathrm{r}}^{\prime}$. The DEM results obtained employing Eq. (3) proposed by Duncan et al. (2007) for a relative density ranging from $65 \%$ to $95 \%$ matches well with the extrapolated field curve obtained using the hyperbolic Eq. (7.3) from Stuedlein (2008) for settlement less than $60 \mathrm{~mm}$. Beyond that value, however, the DEM curve underestimates the settlement in comparison with the extrapolated hyperbolic field curve, similar to what was observed for column V10PW. Because it was difficult to identify the failure pressure on the load displacement curves for column V10PU, the tangent-tangent method was used to determine the bearing capacity as shown in Figure 16 (b). Both the extrapolated hyperbolic curve and the numerical DEM curve provide the same bearing pressure, which is approximately $925 \mathrm{kPa}$ for column V10PU. An additional field data extrapolation was conducted using a third-degree polynomial function. This function fits well with the field data $\left(\mathrm{R}^{2}=0.99\right)$ for both columns, and the DEM curves align better to the polynomial extrapolation than to the hyperbolic field data extrapolation as observed for both piers in Figure $16(a, b)$. 


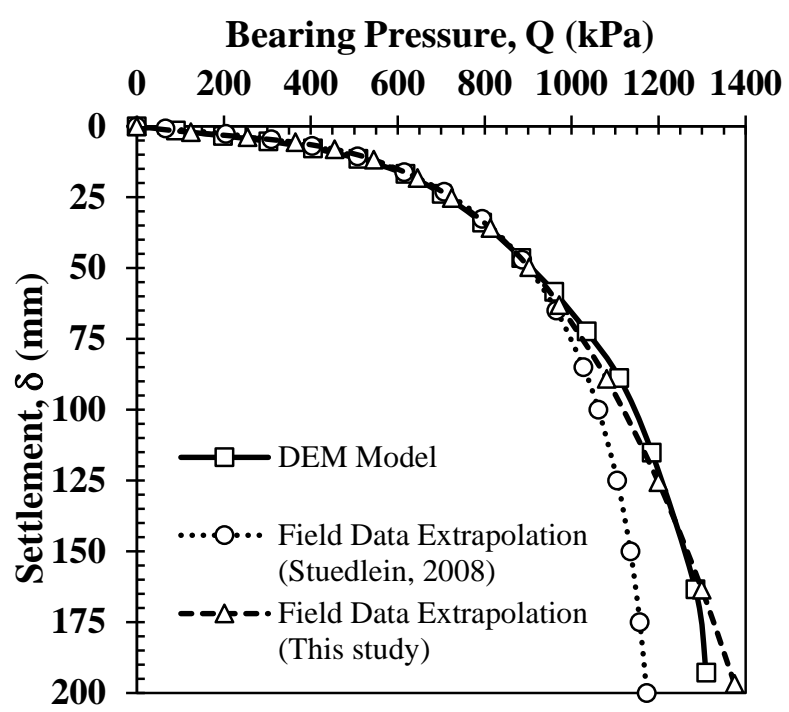

(a) V10PW

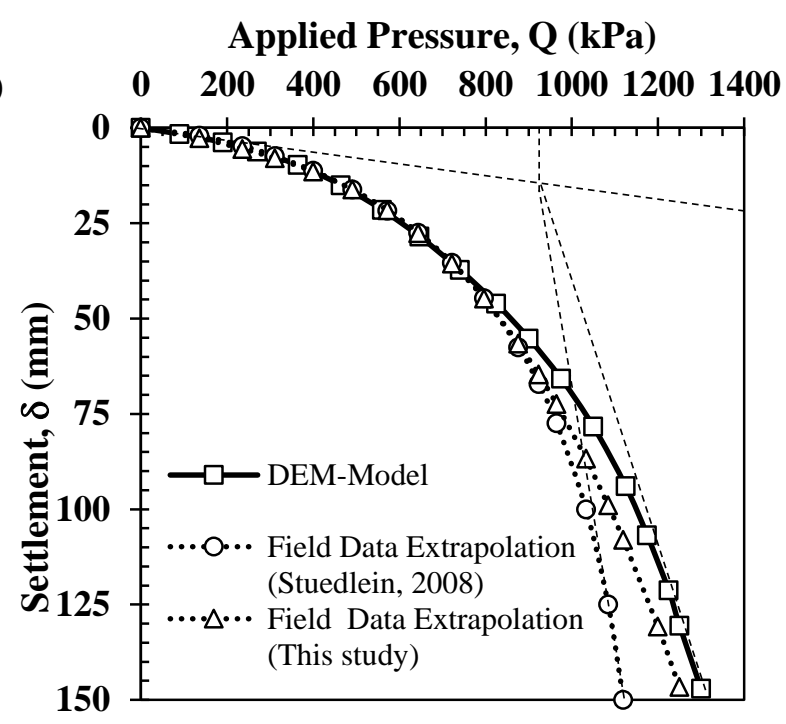

(b) V10PU

Figure 16. Comparison of the full DEM load-displacement for columns (V10PW and V10PU) with extrapolated field data.

Figure 17 (a) shows a comparison of load-displacement curves corresponding to V10PU. Eq. (2) and Eq. (3) proposed by Duncan et al. (2007) were used to vary $\phi_{\text {sc }}^{\prime}$ with $\sigma_{\mathrm{r}}^{\prime}$ for wellgraded and uniformly-graded aggregates, respectively. The DEM curve that corresponds to the uniformly-graded aggregate matches well with the field curve. However, the DEM results for the well-graded aggregate overestimate the settlement observed in the field at all applied pressures. For a $\mathrm{Q}$ equal to $600 \mathrm{kPa}$, the settlement measured in the field and estimated by the DEM simulation for the uniformly-graded aggregate is the same $(24 \mathrm{~mm})$. However, it is approximately $32 \mathrm{~mm}$ for the well-graded aggregate simulation, which represents an error of 33 $\%$ in the settlement estimation. The average confining stress distribution around the column is also affected by the different gradation as illustrated in Figure 17 (b). The $\sigma_{\mathrm{r}}^{\prime}$ develops at the bulging zone for the well-graded aggregate is $44 \%$ greater than for the uniformly-graded aggregate. This is caused by the fact that for the well-graded aggregate ( $21 \mathrm{~b}$ gradation), $\phi_{\mathrm{sc}}^{\prime}$ is 
$10^{\circ}$ less than that for the uniformly-graded aggregate (No. 57 gradation) at the same level of $\sigma_{\mathrm{r}}^{\prime}$ as described in Figure 2.

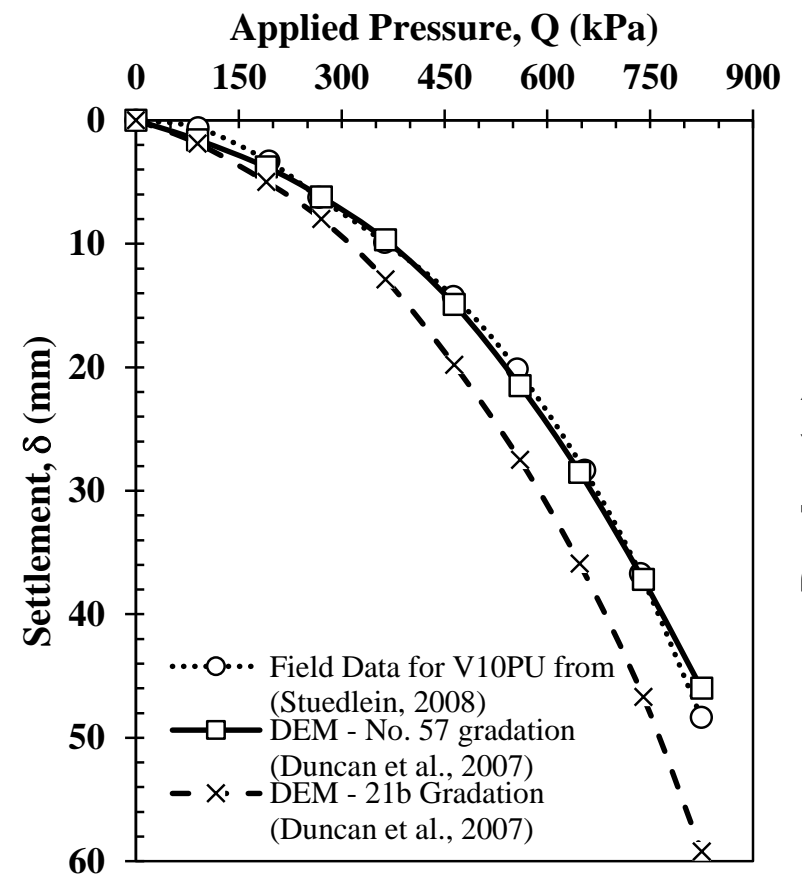

(a)

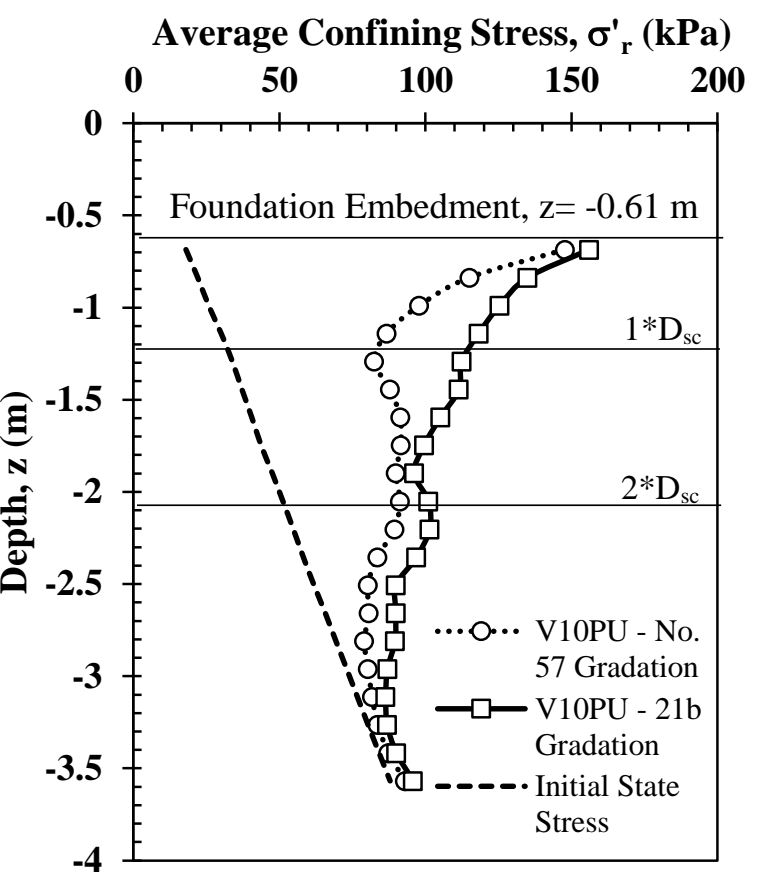

(b)

Figure 17. (a) Comparison of the 3DEM load-displacement curves for No.57 and 21b gradations. (b) Average confining stress with depth.

Figure 18 (a) compares the load-displacement curves corresponding to column V15PU modeled for two different column lengths $(3.05 \mathrm{~m}$ and $4.56 \mathrm{~m})$. The DEM curves for both column lengths lay one over the other for applied pressures less than $800 \mathrm{kPa}$. Beyond this value, there is a slight difference in the load-displacement curve, with the longer column $(4.56 \mathrm{~m})$ providing a settlement of $8 \%$ less than the $3.05 \mathrm{~m}$ long column. Because this difference is insignificant, it is considered than the length is not what is causing the increase in the stiffness of column V15PU with respect to the other columns. A comparison of the load-displacement curves for the column V10PU using Eq. (3) proposed by Duncan et al. (2007) and Eq. (4) developed by Newton (2014) 
is illustrated in Figure 18 (b). No differences are observed between the DEM load-displacement responses, and both of them agree well with the field curve. Therefore, even when the gradations investigated by Duncan et al. (2007) are slightly different than those used to construct the piers, the equation proposed by Duncan et al. (2007) is applicable for simulating the six piers numerically investigated in this study.

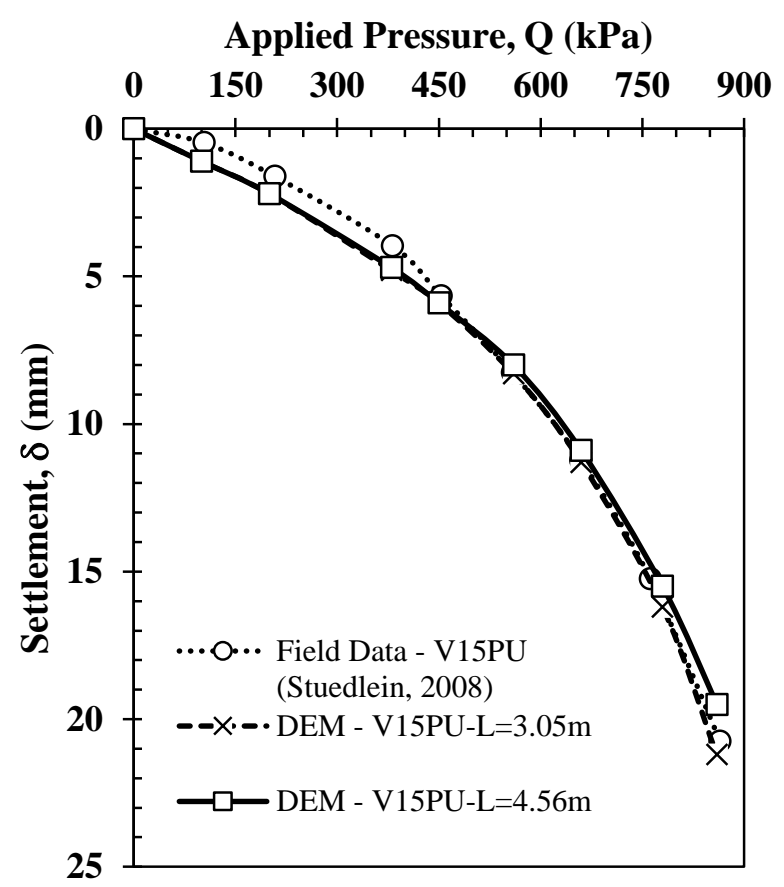

(a)

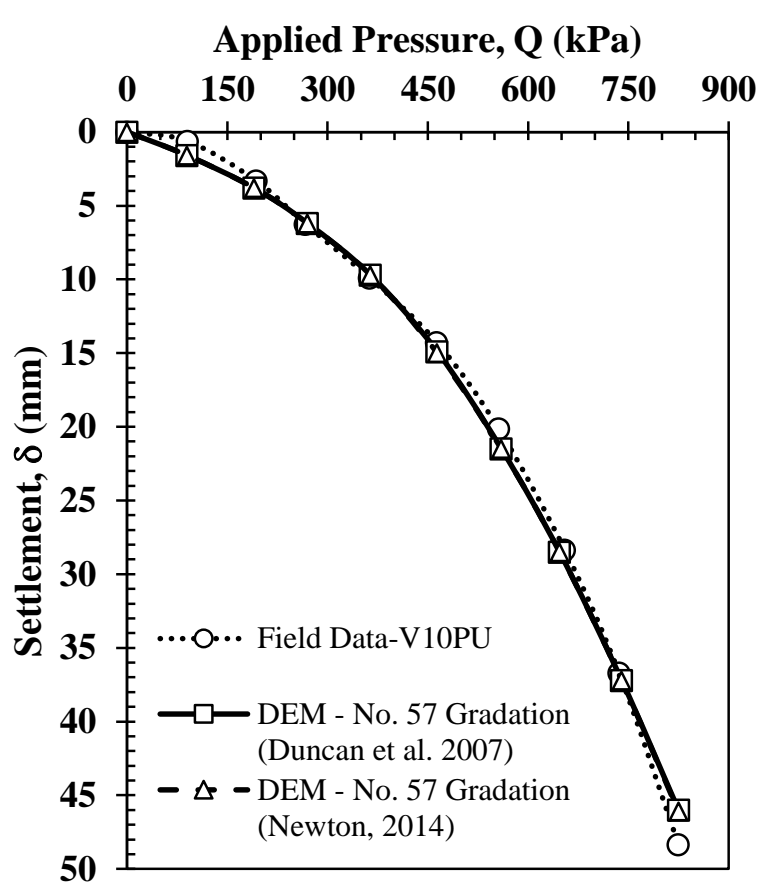

(b)

Figure 18. (a) Comparison of the effect of column length for V15PU. (b) Comparison of the uniformly graded aggregate (No. 57 Gradation).

\section{CONCLUSIONS}

An experimental database collected by Stuedlein (2008) is used to numerically investigate several parameters affecting the global behavior of isolated aggregate columns. The main parameters investigated in this study were: aggregate gradation, confining stress dependence of the aggregate friction angle, and column length and stiffness. A total of six numerical replications of plate load tests conducted on small foundations supported on isolated stone 
columns were evaluated using DEM simulations. The well-graded and uniformly-graded aggregates investigated by Duncan et al. (2007) and Newton (2014) were used to evaluate the variation of aggregate friction angle with the confining pressure. In general, for the six analyzed aggregate piers (V10PW, V10PU, V15PW, V15PU, V10U and V15U), the DEM results provide excellent estimations of the load-displacement curves as compared to the field results. The conclusions given below reflect the main findings of this numerical investigation:

1. Based on the DEM results, using a constant friction angle of $40^{\circ}$ produces conservative load-displacement curves for both gradations while, for a constant friction angle of $50^{\circ}$, the DEM curves obtained for both V10PW and V10PU columns underestimate the field load-displacement curves for applied pressures greater than $600 \mathrm{kPa}$. For a constant friction angle of $45^{\circ}$, the DEM simulations provide much better estimations of the field load-displacement curves than those obtained using $40^{\circ}$ and $50^{\circ}$ for both gradations.

2. The bulging zone depth does not appear to be affected by the length of the column; however, it strongly depends on the diameter of the column and the undrained shear strength profile.

3. The maximum radial displacement for columns with well-graded aggregate is around 8 $\mathrm{mm}$, while for columns with uniformly-graded aggregate, it varies between $2 \mathrm{~mm}$ to 4 $\mathrm{mm}$. This is due to the fact that the friction angle for the uniformly well-graded aggregate is approximately $10^{\circ}$ less than that for the uniformly-graded aggregate at the same confining pressure. For both types of columns, the lateral displacement is negligible for radial distances greater than $2 \mathrm{D}_{\mathrm{sc}}$ away from the center of the column.

4. The confining pressure distribution within the bulging zone is well defined for columns V10PW and V15PW. However, for the columns with uniformly-graded aggregate, there 
is more variation in the confining pressure distribution. This is a result of the replacement area ratio. For V10PW and V15PW, the replacement area is equal to 100\%; therefore, the applied pressure is directly transferred to the column surface. In the case of the uniformly-graded aggregate columns, the replacement area varies from 93\% to 97\%, which causes an increase in $\sigma_{\mathrm{r}}^{\prime}$ beneath the foundation.

5. For the well-graded aggregate columns, the maximum confining pressure predicted by the DEM simulations is around $160 \mathrm{kPa}$ at a depth of $\mathrm{D}_{\mathrm{sc}}$ for an applied pressure of 885 $\mathrm{kPa}$, which represents a confining stress increase of $120 \mathrm{kPa}$ with respect to the initial stress state. On the other hand, for the uniformly-graded aggregate columns, the maximum average confining stress is approximately $120 \mathrm{kPa}$ for an applied pressure of $800 \mathrm{kPa}$.

6. No increase in the confining stress is observed at the bulging zone for applied pressures less than $300 \mathrm{kPa}$. This is because the stone column is stiffer than the surrounding soil, and the replacement area ratios are close to $100 \%$; therefore, the column takes most of the initial applied pressure.

7. The dependence of the aggregate friction angle on gradation was shown to affect the load-displacement response. For the column V10PU, a settlement of $24 \mathrm{~mm}$ is predicted by the DEM simulation when the aggregate friction angle is varied according to the No. 57 gradation. However, by changing the aggregate friction angle according to the $21 \mathrm{~b}$ gradation, a settlement of $32 \mathrm{~mm}$ was estimated by the DEM simulation under the same applied pressure. This represents an error of $33 \%$ at the level of foundation serviceability. Also, a $44 \%$ higher increase in the confining pressure at the bulging zone is observed for the $21 \mathrm{~b}$ gradation compared to the No. 57 gradation. 
Incorporating a friction angle-gradation dependence in the DEM model improves the ability to capture the load-displacement response of the stone columns at the level of foundation serviceability, as well as the ultimate load condition. Therefore, it is recommended that this gradation dependence be incorporated in the design of aggregate columns which fit into the bounds of the data and load conditions used in this study.

This study was limited to plate load tests; however, in many cases, stone columns are subjected to different types of load application. These methods have significant effects on the vertical and confining stress distributions in the adjacent soil as well as in the bulging zone. Therefore, based on the excellent 3D-DEM model calibration with respect to the field results, this 3D-DEM models can be used to evaluate other load scenarios to determine if the variation of the aggregate friction angle with the confining pressure should be considered for any load condition.

\section{REFERENCES}

Ambily, A. P., and Gandhi, S. R. (2007). "Behavior of stone columns based on experimental and FEM analysis.” J. Geotech. Geoenviron. Eng., 133(4), 405-415.

Bouassida, M., and Frikha, W. (2015). "Prediction of stone column ultimate bearing capacity using expansion cavity model." Ground Improv., 168, 106-115.

Brauns, J. (1978). "Die anfangstraglast von schottersäulen im bindigen untergrund." Bautechnik, 55(8), 263-271.

Cundall, P. A. (1988). Formulation of a Three-dimensional Distinct Element Model-Part I. A Scheme to Detect and Represent Contacts in a System Composed of Many Polyhedral Blocks. Rock Mechanics and Geomechanics, 107-116.

Duncan, J. M., Brandon, T., Jian, W., Park, Y., Griffith, T., Corton, J., and Ryan, E. (2007). "Densities and friction angles of granular materials with standard gradations $21 \mathrm{~b}$ and \#57." Center for Geotechnical Practice and Research, Virginia Polytechnic Institute. 
Herle, I., Wehr J., and Arnold, M. (2008). "Soil improvement with vibrated stone columns: influence of pressure level and relative density on the friction angle" International conference on the geotechnics of soft soils, 235-240.

Hughes, J. M. O., and Withers, N. J. (1974). "Reinforcing of soft cohesive soils with stone columns.” Ground Eng., 7(3), 42-49.

Hughes, J. M. O., Withers, N. J. and Greenwood, D. A. (1975). “A field trial of reinforcing effect of a stone column in soil." First Symposium on ground treatment by deep compaction., London, England, 31-41.

Itasca Consulting Group Inc. (2013) 3DEC Version 5.0 User's Guide, Minneapolis, Minnesota USA.

Luding, S. (2008). Introduction to Discrete Element Methods. Discrete Modelling of Geomaterials, 785-826.

McCabe, B. A., and Nimmons, G. J. (2009). "A review of field performance of stone columns in soft soils." Geotech. Eng., 162, 323-334.

Nazari, J. and Ghazavi, M. (2012). "A simple analytical method for calculation of bearing capacity of stone columns.” Int. J. Civil Eng., Vol. 12, 15-25.

Newton, C. R. (2014). "Drained Response of Uncemented and Cemented Aggregates used with Aggregate Pier Ground Improvement." Master thesis, Oregon State University.

Ngo, N. T., Indraratna, B. and Rujikiatkamjorn, C. (2016). "Load-deformation behavior of a stone column using the coupled DEM-FDM method." Proceedings of the joint geotechnical and structural engineering congress., 1618-1626

Stuedlein, A. W. (2008). "Bearing capacity and displacement of spread footings on aggregate pier reinforced clay." Ph.D. thesis, Univ. of Washington, Seattle.

Stuedlein, A. W., and Holtz, R. D. (2010). "Undrained displacement behavior of spread footings in clay." The art of foundation engineering practice, honoring Clyde N. Baker, Jr., P.E., S.E., GSP 198, ASCE, Reston, VA, 653-669.

Stuedlein, A. W., and Holtz, R. D. (2012). "Analysis of footing load tests on aggregate pier reinforced clay.” J. Geotech. Geoenviron. Eng., 138, 1091-1103.

Stuedlein, A. W., and Holtz, R. D. (2013). "Bearing capacity of spread footings on aggregate pier reinforced clay.” J. Geotech. Geoenviron. Eng., 139(1), 49-58.

Vahedian, A., Mahini, S., and Aghdaei, S. (2013). "A short state of the art review on construction and settlement of soft clay soil reinforced with stone column." Int. J. Eng. Tech., Vol. 6, 420-425 
Zhang, L., Zhao, M., Shi, C., and Zhao, H. (2013). "Settlement calculation of composite foundation reinforced with stone columns." J. Geomech., 248-256. 